\title{
Mannose receptor is a restriction factor of HIV in macrophages and is counteracted by the accessory protein $\mathrm{Vpr}$
}

Jay Lubow ${ }^{1}$, David R. Collins ${ }^{1}$, Mike Mashiba ${ }^{2}$, Brian Peterson ${ }^{3}$, Maria Virgilio ${ }^{4}$, Kathleen L Collins ${ }^{* 1,2,4,5}$

1. Department of Microbiology \& Immunology, University of Michigan, Ann Arbor, MI, 48104, USA

2. Graduate Program in Immunology, University of Michigan, Ann Arbor, MI, 48104, USA

3. Department of Biochemistry, University of Michigan, Ann Arbor, MI, 48104, USA

4. Program in Cellular and Molecular Biology, University of Michigan, Ann Arbor, Michigan, United States of America

5. Department of Internal Medicine, University of Michigan, Ann Arbor, MI, 48104, USA

*Correspondence: klcollin@med.umich.edu 


\section{Abstract}

48 HIV-1 Vpr is necessary to support HIV infection and spread in macrophages. Evolutionary

49 conservation of Vpr suggests an important yet poorly understood role for macrophages in HIV

50 pathogenesis. Vpr counteracts a previously unknown macrophage-specific restriction factor that

51 targets and reduces the expression of HIV Env. Here, we report that the macrophage mannose

52 receptor $(\mathrm{MR})$, is the restriction factor targeting Env in primary human monocyte-derived

53 macrophages. Vpr acts synergistically with HIV Nef to target distinct stages of the MR

54 biosynthetic pathway and dramatically reduce MR expression. Silencing MR or deleting mannose

55 residues on Env rescues Env expression in HIV-1-infected macrophages lacking Vpr. However, we

56 also show that disrupting interactions between Env and MR reduces initial infection of

57 macrophages by cell-free virus. Together these results reveal a Vpr-Nef-Env axis that hijacks a

58 macrophage mannose-MR response system to facilitate infection while evading MR's normal

59 role, which is to trap and destroy mannose-expressing pathogens.

60 


\section{Introduction}

Vpr is a highly conserved HIV accessory protein that is necessary for optimal replication in macrophages (Balliet, Kolson et al. 1994) but its mechanism of action is poorly understood. Studies using human lymphoid tissue (HLT), which are rich in both T cells and macrophages, have found that loss of Vpr decreases virus production (Rucker, Grivel et al. 2004) but only when the virus strain used is capable of efficiently infecting macrophages (Eckstein, Sherman et al. 2001). These studies provide evidence that $\mathrm{Vpr}$ enhances infection of macrophages and increases viral burden in macrophage containing tissues. Because Vpr is packaged into the virion (Cohen, Dehni et al. 1990) and localizes to the nucleus (Lu, Spearman et al. 1993), it may enhance early viral replication events. However, mononuclear phagocytes infected with viral particles in which $\mathrm{Vpr}$ is provided by trans-complementation in the producer cells still have a vprnull phenotype (Connor, Chen et al. 1995), indicating that Vpr's role in the HIV replication cycle continues into late stages.

Previous work by our group demonstrated that Vpr counteracts an unidentified, macrophagespecific restriction factor that targets Env and Env-containing virions for lysosomal degradation (Mashiba, Collins et al. 2014, Collins, Lubow et al. 2015). This restriction could be conferred to permissive HEK293T cells by fusing them with MDM to create HEK293T-MDM heterokaryons. A follow up study demonstrated that by increasing steady state levels of Env, Vpr increases formation of virological synapses between infected MDM and autologous, uninfected T cells (Collins, Lubow et al. 2015). This enhances spread to T cells and dramatically increases levels of Gag p24 in the culture supernatant. This finding helps explain the paradoxical observations that Vpr is required for maximal infection of T cells in vivo (Hoch, Lang et al. 1995) but numerous studies have shown Vpr only marginally impacts infection of pure T cell cultures in vitro [e.g. (Mashiba, Collins et al. 2014)]. 
88 Our goal in the current study was to identify and characterize the myeloid restriction factor

89 targeting Env that is counteracted by Vpr. We reasoned that macrophage-specific Env-binding 90 proteins, including the carbohydrate binding protein mannose receptor (MR), were candidates.

$91 \mathrm{MR}$ is expressed on several types of macrophages in vivo (Liang, Shi et al. 1996, Linehan,

92 Martinez-Pomares et al. 1999) and is known to mediate innate immunity against various

93 pathogens (Macedo-Ramos, Batista et al. 2014, Subramanian, Neill et al. 2019). MR recognizes

94 mannose rich structures including high-mannose glycans, which are incorporated in many

95 proteins during synthesis. In eukaryotic cells most high-mannose glycans are cleaved by $\alpha$ -

mannosidases and replaced with complex-type glycans as they transit through the secretory

97 pathway. By contrast, in prokaryotic cells, high-mannose residues remain intact, making them a

Env, evade mannose trimming (Coss, Vasiljevic et al. 2016) and retain enough high-mannose to bind MR (Trujillo, Rogers et al. 2007, Lai, Bernhard et al. 2009). There is evidence that HIV-1 proteins Nef and Tat decrease expression of MR based on studies performed in monocyte derived macrophages (MDM) and the U937 cell line, respectively (Caldwell, Egan et al. 2000, Vigerust,

103 Egan et al. 2005). Nef dysregulates MR trafficking using an SDXXLФ motif in MR's cytoplasmic

104 tail (Vigerust, Egan et al. 2005), which is similar to the sequence in CD4's tail that Nef uses to 105 remove it from the cell surface (Bresnahan, Yonemoto et al. 1998, Greenberg, DeTulleo et al. 106 1998, Cluet, Bertsch et al. 2005). Whether MR or its modulation by viral proteins alters the course 107 of viral replication has not been established.

109 Here, we confirm that Nef reduces MR expression in primary human MDM, although in our system, the effect of Nef alone was relatively small. In contrast, we report that co-expression of

111 Vpr and Nef dramatically reduced MR expression. In the absence of both Vpr and Nef, MR levels 112 normalized indicating that Tat did not play a significant, independent role in MR downmodulation. 
113 Deleting mannose residues on Env or silencing MR alleviated mannose-dependent interactions

114 between MR and Env and reduced the requirement for $\mathrm{Vpr}$. Although the post-infection

115 interactions between MR and Env reduced Env levels and inhibited viral release, we provide

116 evidence that these same interactions were beneficial for initial infection of MDM. Together these

117 results reveal mannose residues on Env and the accessory proteins Nef and Vpr are needed for

118 HIV to utilize and then disable an important component of the myeloid innate response against

119 pathogens intended to thwart infection. 


\section{Results}

122

\section{Identification of restriction factor counteracted by Vpr in primary human monocyte-derived}

124 macrophages. Because we had previously determined that Vpr functions in macrophages to 125 counteract a macrophage selective restriction factor that targets Env, we reasoned that Env126 binding proteins selectively expressed in macrophages were potential candidate restriction

127 factors. To determine wether any factors fitting this description were targeted by $\mathrm{Vpr}$, we 128 performed western blot analysis of candidate Env binding proteins in MDM matched for wild type 129 or Vpr null HIV infection frequency (Figures 1A and B). We found that one such protein, mannose 130 receptor (MR), which is highly expressed on macrophages and has been previously shown to 131 bind Env (Trujillo, Rogers et al. 2007, Fanibunda, Velhal et al. 2008, Lai, Bernhard et al. 2009), 132 was significantly decreased by wild type HIV 89.6 but not by 89.6 vpr-null (Figure 1C and D, $133 p<0.01)$.

135 To confirm the effect of Vpr on Env during infections or primary human macrophages in which 136 MR was downmodulated, we performed quantitiative western blot analysis. As shown in Figures 137 1E and $F$, we confirmed that amounts of Vpr sufficient for MR downmodulation were also sufficient 138 for stabilizing expression of Env (gp160, gp120, gp41). Compiled data from nine donors clearly 139 demonstrated results that were similar to our prior publication (Mashiba, Collins et al. 2014); under 140 conditions of matched infection in which there was no significant difference in pr55 levels between 141 wild type and vpr-null infections, all three forms of Env were significantly more abundant in the 142 wild type infection (gp160: 4-fold, $p<0.002$; gp120: 6-fold, $p<0.002$; gp41: 4-fold, $p<0.001$ ).

144 Combined effects of Nef and Vpr have dramatic effects on MR levels in a subset of infected

145 cells. Because an earlier report indicated that Nef decreases surface expression of MR (Vigerust, 146 Egan et al. 2005), we asked whether Nef was playing a role in MR downmodulation in our 147 systems. Because HIVs lacking Vpr and Nef spread too inefficiently in MDM to observe effects 
on host proteins by western blot analysis, we utilized a replication defective HIV with a GFP marker (NL4-3 $\triangle$ GPE-GFP) to allow measurement of MR expression via flow cytometry following single-round transduction. This construct has the additional advantage that it eliminates

151 potentially confounding effects of differences in wild type and Vpr-null viral spread. Therefore, we

152 generated the necessary mutations in nef and $v p r$ and confirmed that these mutations only

153 affected expression of the altered gene product in transfected HEK293T (Figure 2B). For

154 experiments in primary human macrophages, MDM were harvested at earlier times than the

155 experiments described in Figure 1 (five days versus ten days) because of the non-spreading

156 nature of the virus and the capacity to use flow cytometry to identify the subset of infected cells

157 by GFP expression (Figure 2C). Under these conditions, we found that MR expression was

158 dramatically reduced in a subset of GFP ${ }^{+}$cells when both Vpr and Nef were expressed (Figure

159 2C-E). Loss of function mutations in either Vpr or Nef led to modest but statistically significant MR

160 downmodulation in a subset of cells. Combined loss of both Nef and Vpr virtually eliminated MR

161 downmodulation (Figure 2D and E). These differences in MR downmodulation were not due to

162 variations in multiplicity of infection of the different viral constructs as MDM transduced with the

163 mutant viral constructs had roughly similar or slightly higher transduction rates as the parental

164 construct (Figure 2F) but demonstrated less MR downmodulation (Figure 2E).

166 To determine whether the modest effect of Nef alone was due to using HIV to deliver Nef as 167 compared to an adenoviral vector delivery system used in a prior publication (Vigerust, Egan et 168 al. 2005), we repeated the experiment using an adenoviral vector expressing Nef. These 169 experiments confirmed that levels of Nef sufficient to downmodulate the HIV receptor, CD4 on 170 nearly all MDM in the culture achieved only modest effects on MR in a subset of cells (Figure 2G) 171 similar to what was observed using the HIV reporter construct (Figure 2E). Thus, Nef and Vpr 172 have modest but significant effects on MR when expressed individually, however the combined 
173 effects of both proteins can achieve nearly complete downmodulation at least in a subset of

174 infected cells.

175

176 While the effect of Nef has been previously reported and found to be due to disruption of MR

177 intracellular trafficking (Vigerust, Egan et al. 2005), the effect of Vpr on MR has not been

178 previously reported. Vpr is known to target cellular proteins involved in DNA repair pathways for

179 proteasomal degradation via interactions with Vpr binding protein [DCAF1, (McCall, Miliani de

180 Marval et al. 2008)], a component of the cellular DCAF1-DDB1-CUL4 E3 ubiquitin ligase complex

181 (Belzile, Duisit et al. 2007, Hrecka, Gierszewska et al. 2007, Le Rouzic, Belaidouni et al. 2007,

182 Wen, Duus et al. 2007, Lahouassa, Blondot et al. 2016, Wu, Zhou et al. 2016, Zhou, DeLucia et

183 al. 2016). Using this mechanism, Vpr degrades the uracil deglycosylases UNG2 and SMUG1 in

184 HEK293T cells following co-transfection (Schrofelbauer, Yu et al. 2005, Schrofelbauer, Hakata et

al. 2007). To determine whether Vpr directly targets MR using a similar strategy, we cotransfected NL4-3 $\triangle$ GPE-GFP or a Vpr-null derivative and an expression vector encoding MR under the control of a cytomegalovirus (CMV) promoter [pCDNA.3.hMR (Liu, Liu et al. 2004)] in HEK293T cells and analyzed MR expression by flow cytometry as shown in Fig S1. We found that Vpr in HEK293T cells had no effect on expression of MR controlled by a heterologous CMV promoter (Figure 2G and S1). Thus, we concluded that Vpr does not degrade MR by the direct mechanism it uses to degrade UNG2 and SMUG1.

In addition to targeting proteins for degradation, $\mathrm{Vpr}$ also functions to inhibit transcription of genes

194 such as IFNA1 (Laguette, Bregnard et al. 2014, Mashiba, Collins et al. 2014). Therefore, we 195 hypothesized that Vpr may reduce MR expression via inhibition of transcription. To examine this, 196 we again utilized infected primary human MDM expressing MR under its native promoter that 197 were transduced with the wild type or Vpr-null reporter virus (Figure 2A). To isolate a uniform 198 population of infected cells necessary for such an analysis, we used fluorescence activated cell 
sorting to purify transduced $\left(\mathrm{GFP}^{+}\right)$cells. Indeed, in this system we observed a reduction in MR gene $(M R C 1)$ expression in transduced $\left(G^{+} P^{+}\right)$samples in a Vpr-dependent manner $(p=0.03$,

201 Figure $2 \mathrm{H}$ ). The magnitude of this effect is consistent with prior reports of HIV-1 inhibiting MRC1

202 transcription- though this was not previously linked to Vpr (Koziel, Eichbaum et al. 1998, 203 Sukegawa, Miyagi et al. 2018).

Combined effect of Vpr and Nef dramatically enhances Env levels in primary human MDM.

To determine whether the striking downmodulation of MR we observed with expression of both Nef and Vpr affected viral spread in $\mathrm{MR}^{+}$macrophages, we generated additional mutations in HIV189.6 to create a nef-null mutant and a vpr-nef-null double mutant. As expected, in transfected HEK293T cells these mutations did not alter Env protein levels (Figure 3A) or release of virions as assessed by measuring Gag p24 into the supernatant by ELISAs (Figure 3B). However, in

211 primary human MDM infected with these HIVs, the mutants demonstrated defects in viral spread,

212 with the combination double mutant having the greatest defect (Figure 3C and 3D). The defect in

213 spread was caused in part by diminished virion release, which we previously showed occurred in

214 the absence of Vpr (Mashiba, Collins et al. 2014); MDM infected with the HIV mutants released

215 less Gag p24 even after adjusting for the frequency of infected cells (Figure 3D, right panel),

217 To determine whether the striking downmodulation of MR we observed with expression of both

218 Nef and $\mathrm{Vpr}$ affected Env restriction in $\mathrm{MR}^{+}$macrophages, we assessed Env levels in primary

219 human MDM infected with each construct. Because the frequency of infected cells as assessed

220 by intracellular Gag staining (Figure 3C) and Gag pr55 expression as measured by western blot

221 was lower in the mutants than in the wild type infection (Figure 3E), lysate from the wild type

222 sample was serially diluted to facilitate comparisons. Remarkably, we found that the vpr-nef-null

223 double mutant, which retains near normal MR levels exhibited the greatest defect in Env 224 expression (Figure 3E, compare lanes with similar Gag as indicated). Mutation of vpr and nef 
225 individually, which greatly increased MR levels compared to wild type HIV infection, also led to 226 striking defects in Env expression. In sum, the effect of Vpr and Nef we observed on MR correlated

227 inversely with Env levels, consistent with MR being the previously reported restriction factor in 228 primary human MDM that restricts Env expression by accelerated lysosomal degradation and 229 which is counteracted by Vpr (Mashiba, Collins et al. 2014). In the case of Vpr, this is likely solely 230 due to downmodulation of MR. In the case of Nef, combined effects on MR and other Env binding 231 proteins including CD4 (Aiken, Konner et al. 1994) and chemokine receptors (Michel, Ganter et 232 al. 2006) may play a role.

Evidence for a role for mannose-containing glycan in restriction of Env in primary human

MDM. Previously reported interactions between HIV Env and MR are believed to occur via mannose-containing glycans on Env. Interestingly, the macrophage tropic strain YU-2, which was isolated from the CNS of an AIDS patient (Li, Kappes et al. 1991), lacks a glycan structure known as the mannose patch. This structure is the target of several broadly neutralizing antibodies including 2G12, to which YU-2 is highly resistant (Trkola, Purtscher et al. 1996). We hypothesized that loss of the mannose patch would decrease interactions with MR and reduce the requirement for Vpr to counteract MDM-specific restrictions to virion release and Env expression. To test this hypothesis we examined the extent to which virion release and Env expression were influenced by Vpr in primary human MDM infected with YU-2 or 89.6 HIVs. Remarkably, we observed no significant difference in Gag p24 release between wild type and vpr-null YU-2 infection of MDM (Figure 4A). Moreover, the vpr-null mutant of YU2 displayed only a minor defect in Env expression compared to Vpr null versions of 89.6 and NL4-3 (Figure 4B).

Because there are a number of other genetic differences between $\mathrm{YU}-2$ and the other HIVs, we constructed a chimeric virus, which restricted the differences to the env open reading frame. As

250 shown in Figure 4C, a fragment of the $\mathrm{YU}-2$ genome containing most of env but none of $v p r$ 
251 (Figure 4C, shaded portion) was cloned into NL4-3 and NL4-3 vpr-null. As expected, these genetic

252 alterations did not affect Env protein levels or virion release in transfected HEK293T cells (Figure

$2534 \mathrm{D}$ and E). To confirm that the chimeric Env was still functional, we examined infectivity in T cells

254 prior to performing our analyses in primary human MDM. Conveniently, sequence variation within

255 the gp120 region allows YU-2 Env to only utilize the co-receptor CCR5 for entry, whereas NL4-3

256 can only utilize CXCR4. Thus, we expected the NL4 3env ${ }^{\mathrm{YU} 2}$ chimera would switch from being

257 CXCR4- to CCR5-tropic. To test this, we utilized a T cell line expressing both chemokine receptors

258 (MOLT4-R5) and selectively blocked entry via CXCR4 and CCR5 entry inhibitors [AMD3100 and

259 maraviroc, respectively (Figure 4F)]. As expected, entry of MOLT4-R5 cells by NL4-3 was blocked

260 by AMD3100 but not maraviroc, indicating CXCR4-tropism. The chimeric NL4-3 env ${ }^{\text {YU2 }}$ and wild

261 type YU-2 demonstrated the reverse pattern, indicating CCR5-tropism. These results

262 demonstrated that we had made the expected changes in the chimeric Env without disrupting its

263 capacity to infect cells.

264

265 To determine whether swapping a limited portion of YU-2 containing Env into NL4-3 alleviated

266 the requirement for $\mathrm{Vpr}$, we examined Env expression and virion release in primary human MDM

267 infected with these viruses. Because the parental NL4-3 virus required pseudotyping with a

268 macrophage-tropic Env for entry and was unable to spread in MDM, all infections were treated

269 with entry inhibitors AMD3100 and maraviroc 48 hours after inoculation to block subsequent

270 rounds of infection. Remarkably, we observed that wild type NL4-3 Env but not chimeric NL4-3

271 env ${ }^{\mathrm{YU} 2}$ required $\mathrm{Vpr}$ for maximal expression (Figure 4G). Moreover, MDM infected with the

272 chimeric HIV had a reduced requirement for $\mathrm{Vpr}$ for maximal virion release (Figure $4 \mathrm{H}$ ). This

273 experiment provides strong evidence that the requirement for $\mathrm{Vpr}$ can be alleviated by genetic

274 changes within the env open reading frame. These results are consistent with a model in which

$275 \mathrm{YU}-2$ env confers resistance to the effects of MR due to the absence of the mannose rich structure

276 on the YU-2 Env glycoprotein. 
Deletion of $\mathrm{N}$-linked glycosylation sites in Env reduces Env restriction in HIV-1 infected human primary MDM and diminishes the need for Vpr and Nef. To more directly assess the role of mannose in restricting expression of Env in HIV-1 infected primary human MDM, we engineered a version of 89.6 Env in which two N-linked glycosylation sites, N230 and N339 (HIV HxB2 numbering) were substituted for amino acids found at analogous positions in YU-2 Env (Figure 5A). The glycosylation sites N2330 and N339 were selected because they contain highmannose glycan structures (Leonard, Spellman et al. 1990) that are absent in YU-2 Env. Loss of N230 limits neutralization by glycan specific antibodies (Huang, Kang et al. 2014). Loss of N339 decreases the amount of oligomannose $\left(\mathrm{Man}_{9} \mathrm{GlCNAc}_{2}\right)$ present on gp120 by over $25 \%$, presumably by opening up the mannose patch to processing by $\alpha$-mannosidases (Pritchard, Spencer et al. 2015). These substitions (N230D and N339E) in 89.6 did not alter virion production (Figure 5B) or Env protein expression (Figure 5C) in transfected HEK293T cells.

To confirm that mutation of N230 and N339 disrupted the mannose patch on Env, we assayed the ability of $2 \mathrm{G} 12$, which recognizes epitopes in the mannose patch (Sanders, Venturi et al. 2002, Scanlan, Pantophlet et al. 2002), to neutralize wild type and mutant Env. As shown in Figure 5D, wild type but not mannose deficient N230D N339E was neutralized by 2G12. In addition, we found that these substitutions did not disrupt infection of a T cell line that does not express MR (Figure 5E). However, somewhat unexpectedly, we found that HIV containing the N230D N339E Env

297 substitutions were approximately $40 \%$ less infectious to primary human macrophages expressing

298 MR than the wild type parental virus (Figure 5E). This macrophage-specific difference in infectivity 299 suggested that mannose on Env facilitates initial infection through interactions with MR, which is 300 highly expressed on differentiated macrophages. To examine this possibility further, we asked 301 whether mannan, which competitively inhibits MR interactions with mannose containing glycans 302 (Shibata, Metzger et al. 1997), was inhibitory to HIV infection. As a negative control, we tested 
89.6 $\Delta$ env pseudotyped with vesicular stomatitls virus G-protein Env (VSV-G) which has only two $\mathrm{N}$-linked glycosylation sites, both of which contain complex-type rather than high-mannose glycans (Reading, Penhoet et al. 1978) and therefore should not bind MR or be inhibited by mannan. As expected, we found that infection of a T cell line lacking MR was not sensitive to mannan (Figure 5F, left panel). However, infection of MDM by wild type HIV-1 was inhibited up to 16-fold by mannan. This was specific to HIV Env because mannan did not inhibit infection by HIV lacking env and pseudotyped with the heterologuos VSV-G Env (Figure 5F). Interestingly, mannan also inhibited baseline macrophage infection by mannose-deficient Env (89.6 Env N230D N339E), indicating that N230D N339E substitutions did not completely abrogate glycans on Env

312 that are beneifical to initial infection. In sum, our results demonstrate that interactions with mannose binding receptors are advantageous for initial HIV infection of macrophages and that

314 the glycans remaining on Env N230D N339E retain some ability to bind glycan receptors on macrophages that facilitate infection.

317 While interactions between high-mannose residues on Env and MR are advantageous for viral entry, we hypothesized that they interfered with intracellular Env trafficking and were deleterious to egress of Env-containing virions in the absence of Vpr and/or Nef. To test this, we examined 320 virion release and Env expression by HIVs encoding the mannose-deficient Env N230D N339E 321 plus or minus Vpr expression. We found that mannose-deficient Env had a reduced requirement 322 for Vpr for maximal virus relase compared with the parental wild type virus in a spreading infection 323 system (Figure 5G, $p<0.001$ ). In addition, the mannose-deficient Env had a reduced requirement 324 for both Nef and Vpr in virion release assays using primary human MDM infected for a single 325 round of infection (Figure $5 \mathrm{H}, \mathrm{p}<0.001$ ). Single round infection assays were used to assess the 326 vpr-nef double mutant because depletion of mannose on Env did not rescue spread. This is likely 327 due to pleiotropic effects of Nef that disrupt interference by the HIV receptors, CD4, CXCR4 and 
CCR5 (Lama, Mangasarian et al. 1999, Michel, Allespach et al. 2005, Venzke, Michel et al. 2006) combined with the reduced infectivity of the mannose deficient Env.

Finally, we asked whether the mannose-deficient Env had increased stability in primary human MDM lacking Vpr and/or Nef by western blot analysis. Remarkably, we found that the mannosedeficient Env rescued Env expression in the absence of Vpr (Figure 5I, right side, black bars),

334 and reduced the defect observed in the vpr-nef-null double mutant (Figure 5I, right side, gray

335 bars) once differences in infection frequency were accounted for by matching pr55 expression in

336 the dilution series. These data provide strong support for the model that MR restricts Env

337 expression via direct interaction with high-mannose residues on Env and that this restriction is counteracted by Vpr and Nef.

Silencing MR alleviates restriction of Env in primary human MDM lacking Vpr. To directly test the hypothesis that MR is the restriction factor in MDM that is counteracted by Vpr, we examined the effect of MR silencing on Env expression in HIV-infected MDM lacking Vpr.

343 Remarkably, we observed that silencing MR markedly reduced Env restriction - once differences

344 in infection frequency as assessed by Gag pr55 expression were accounted for (Figure 6A).

345 These results support the conclusion that the Env restriction observed in vpr-null 89.6 is 346 dependent on expression of MR.

348 Previous work in our lab demonstrated that restriction of Env in primary human MDM disrupted 349 formation of virological synapses and cell-to-cell spread of HIV from infected MDM to T cells 350 (Collins, Lubow et al. 2015). Expression of Vpr alleviated these effects, dramatically increasing 351 viral transmission - especially under conditions of low initial inoculum of free virus. To determine 352 whether MR was responsible for these defects in MDM lacking Vpr, we measured Vpr-dependent 353 HIV-1 spread from primary human MDM silenced for MR to activated primary T cells freshly 
354 isolated from the same donor. In this assay system, co-cultured cells were stained for CD3 to

355 distinguish T cells and CD14 to distinguish MDM as shown in Figure S2. Indeed, we found that

356 silencing MR dramatically reduced the requirement for Vpr to support spread from MDM to T cells

357 (Figure 6D). In addition, MR silencing reduced the need for Vpr in virus release assays in the co-

358 culture system (Figure 6E). These data support the conclusion that MR is the previously identified

359 restriction factor in macrophages that reduces spread from Vpr-null HIV-infected macrophages to

360 T lymphocytes.

Infection of macrophages dramatically facilitates intial infection by transmitter/found (T/F)

363 HIVs involved in intial HIV transmission. Because macrophages are present in genital mucosa,

364 are permissive to HIV infection (Shen, Richter et al. 2009), and recruit HIV-permissive CD4 ${ }^{+} \mathrm{T}^{2}$

365 cells as part of their immunologic function (Liao, Rabin et al. 1999) we wondered whether cell-to-

366 cell spread from MDM to T cells may potentially facilitate transmission. To examine this possibility,

367 we tested two transmitted/founder (T/F) HIV molecular clones (REJO and CH077), which can

368 both cause detectable infection in T cells following spinnoculation (Figure 7A, upper panel) or long

369 term culture (Ochsenbauer, Edmonds et al. 2012), but which differ in their capacity to infect

370 macrophages (Ochsenbauer, Edmonds et al. 2012). We observed that when MDM were

371 inoculated briefly (6 hours) and cultured for two days, REJO produced detectable infection but

$372 \mathrm{CH} 077$ did not (Figure 7A, lower panel). Using the experimental protocol diagrammed in Figure

373 7B, we observed that when $T$ cells were cultured for two days with cell free virus without

374 spinnoculation, both T/F viruses failed to infect a significant fraction of T cells (Figure 7C, upper

375 panel). In contrast, when T cells were co-cultured for two days with MDM that had previously been

376 infected as in Figure 6F, the T/F virus REJO was transmitted to T cells but $\mathrm{CH} 077$ was not (Figure

377 7C, lower panel) Thus, under conditions of limited exposure to cell free virus, macrophage

378 infection can dramatically enhance spread and speed infection to T cells. The role for Vpr in this 
bioRxiv preprint doi: https://doi.org/10.1101/742197; this version posted August 21, 2019. The copyright holder for this preprint (which was not certified by peer review) is the author/funder, who has granted bioRxiv a license to display the preprint in perpetuity. It is made available under aCC-BY 4.0 International license.

379 process likely contributes to its evolutionary conservation in nearly all simian and human lentivirus

380 genomes (Mashiba and Collins 2013).

381 


\section{Discussion}

383 Our findings demonstrate that HIV encodes two accessory proteins, Vpr and Nef, that dramatically 384 reduce expression of $M R$ on infected macrophages and provide an explanation for the 385 evolutionary conservation of Vpr in HIV-1. Our results clearly define MR as a factor capable of 386 restricting the expression of Env and interfering with virion release. While the effect of Nef on MR 387 was previously reported, the effect of $\mathrm{Vpr}$ on MR was entirely unexpected. The evidence that $\mathrm{Vpr}$ 388 counteracts MR to stabilize Env is strong. We demonstrate that Vpr expression correlates with 389 reduced MR expression. In addition, we show that loss of Vpr can be rescued by changes within 390 the Env locus that reduce detrimental interactions with MR, including point mutations that 391 selectively delete mannose residues. Finally, silencing MR expression decreased the requirement 392 for Vpr to stabilize Env and enhanced spread to T cells and virion release.

Other investigators have reported that MR inhibits virion egress in HEK293T cells (Sukegawa, Miyagi et al. 2018). However, this study differed from results we report here in primary human macrophages because the prior study observed effects on virions that were Env-independent. In

397 addition, they did not examine effects of Vpr on MR in their system (Sukegawa, Miyagi et al. 398 2018). In the primary macrophage system, Vpr-senstiive virion restriction depends entirely on an 399 intact env open reading frame (Mashiba, Collins et al. 2014) and genetic changes in the env open 400 reading frame - especially those that alter $\mathrm{N}$-linked glycosylation sites -critically affect the 401 requirement for Vpr. The effect of MR on Env and Env-containing virion release helps explain the 402 significance behind prior in vivo observations demonstrating that HIV infection reduces expression 403 and activity of MR in infected humans (Koziel, Kruskal et al. 1993, Koziel, Eichbaum et al. 1998) 404 and that SIV does the same in monkeys (Holder, McGary et al. 2014). By demonstrating how the 405 effect of Vpr on MR promotes macrophage to T cell spread, we also provide an explanation for 406 how Vpr increases infection of human lymphoid tissue ex vivo (Eckstein, Sherman et al. 2001, 
407 Rucker, Grivel et al. 2004), which contain macrophages and T cells in a highly physiological, 408 three-dimensional environment.

410 As Nef had already been shown to reduce MR surface expression (Vigerust, Egan et al. 2005),

411 the observation that HIV encodes a second protein, Vpr, to reduce MR expression was

412 unanticipated, but not unprecedented; other host proteins are known to be affected by more than

413 one lentiviral accessory protein. The HIV receptor, CD4, is simultaneously targeted by Vpu, Nef

414 and Env in HIV-1 (Chen, Gandhi et al. 1996) and tetherin is alternately targeted by Vpu, Nef, or

415 Env in different strains of primate lentiviruses (Harris, Hultquist et al. 2012). Nef has also been

416 shown to downmodulate the viral co-receptors CXCR4 (Venzke, Michel et al. 2006) and CCR5

417 (Michel, Allespach et al. 2005), which may also interfere with Env expression in infected cells.

418 Nef's activity against CXCR4, CCR5, and MR presumably has the same ultimate purpose as its

419 activity against CD4, namely to stabilize Env, enhance virion release and prevent superinfection

420 of the producer cell (Lama, Mangasarian et al. 1999, Ross, Oran et al. 1999). The need for Vpr

421 and Nef to simultaneously target MR may be explained by the high level of MR expression,

422 estimated at 100,000 copies per macrophage (Stahl, Schlesinger et al. 1980). Alone, Vpr and Nef

423 each has a modest effect on MR in primary human macrophages. The magnitude of the effect

424 and the fraction of cells affected increased when both proteins were expressed. The potent

425 combined effect likely derives from synergistic targeting of MR at two different stages of MR

426 synthesis. Nef was shown to alter MR trafficking (Vigerust, Egan et al. 2005) and we show Vpr

427 inhibits MR transcription.

429 In sharp contrast to the effect we observed in MDM, Vpr did not affect MR protein levels when

430 MR was expressed via a heterologous promoter in the HEK293T cell line, which is derived from

431 human embryonic kidney cells, which are not a natural target of HIV. The cell type selectivity in

432 these experiments is likely due to differences in the promoters driving MR expression, however, 
433 we cannot rule out the existence of other macrophage specific pathways required to recreate the

434 effect of Vpr on MR. Further work will be needed to examine these questions and determine other

435 mechanistic details. For example, it will be important to determine whether Vpr utilizes its cellular

436 co-factors to affect MR levels. Vpr is perhaps best known for its interaction with Vpr binding protein

437 [DCAF1, (McCall, Miliani de Marval et al. 2008)], a component of the cellular DCAF1-DDB1-CUL4

438 E3 ubiquitin ligase complex that plays a role in Vpr-dependent disruption of the cell cycle and

439 cellular DNA repair pathways in dividing cells (Belzile, Duisit et al. 2007, Hrecka, Gierszewska et

440 al. 2007, Le Rouzic, Belaidouni et al. 2007, Wen, Duus et al. 2007, Lahouassa, Blondot et al.

441 2016, Wu, Zhou et al. 2016, Zhou, DeLucia et al. 2016). This interaction has also been linked to

442 transcriptional inhibition of type I interferons in response to infection in macrophage cultures

443 (Laguette, Bregnard et al. 2014, Mashiba, Collins et al. 2014). Additional research is now needed

444 to determine whether repression of MR and IFN transcription is mediated by the same DCAF-1

445 dependent pathway.

447 Interactions between MR and Env are likely mediated by the unusually high density of $\mathrm{N}$ linked

448 glycosylation sites that retain high-mannose glycans, which is a known PAMP (Stahl and

449 Ezekowitz 1998, McGreal, Rosas et al. 2006). Here, we show that selective deletion of mannose

450 residues alleviated the requirement for Vpr. Deletion of individual glycosylation sites is known to

451 lead to changes in the processing of neighboring glycans and deletions at certain sites lead to

452 larger than expected losses of oligomannose (Balzarini 2007) presumably because their removal

453 allows greater access and facilitates trimming of surrounding glycans. Selective pressure to

454 maintain mannose residues on Env may be due to the enhanced attachment they mediate.

455 Indeed, we provide strong evidence that Env's interaction with MR boosts initial infection of MDM.

456 This finding is supported by a prior report that MR enhances HIV-1 binding to macrophages and

457 transmission of the bound virus to co-cultured T cells (Nguyen and Hildreth 2003). Our study adds

458 to these findings by providing evidence that interactions with mannose binding receptors also 
enhance direct infection of macrophages. Moreover, the capacity of Vpr and Nef to mitigate the

460 effect of detrimental intracellular interactions during viral egress limits the negative impact of

461 retaining high-mannose on Env. In addition, the dense glycan packing, which is privileged from

462 antibody recognition through immune tolerance, is believed to play a role in evasion of the

463 antibody response (Stewart-Jones, Soto et al. 2016).

465 Here we also confirm our prior observation that Vpr enhances transmission of HIV from infected 466 macrophages to primary $\mathrm{T}$ lymphocytes. Macrophages prepared according to our culture 467 conditions are more easily infected by cell free virus in vitro than activated T cells, which require 468 spinoculation for detectable infection following short incubations (48 hours). The observation that 469 T/F viral strains with a greater capacity to infect macrophages have an advantage in our co-culture 470 system suggests a role for $\mathrm{Vpr}$ during transmission. The accelerated spread to $\mathrm{T}$ cells we 471 observed may be critical to establishing a persistent infection before innate and adaptive immune 472 responses are activated. While in vitro assays of T/F viruses have suggested strong evolutionary 473 selection for $\mathrm{T}$ cell infection with limited capacity to infect macrophages, other studies indicate 474 that T/F viruses are generally less infectious to all cell types compared to viruses isolated at other 475 stages (Peters, Gonzalez-Perez et al. 2015), but appear to be selected primarily by their 476 resistance to interferon (lyer, Bibollet-Ruche et al. 2017). The strong selective pressure to retain

477 Vpr despite its limited effect on T cell-only cultures indicates there is more to learn about the role 478 of Vpr, macrophages and T/F viruses in HIV transmission and pathogenesis. Collectively, these 479 studies suggest that novel therapeutic approaches to inhibit the activity of $\mathrm{Vpr}$ and Nef in 480 macrophages would potentially represent a new class of antiretroviral drug that could be an 481 important part of a treatment or prophylactic cocktail. 


\section{Materials and Methods}

\section{Viruses and viral vectors}

485 The following molecular clones were obtained via the AIDS Reagent Program: p89.6 (cat\# 3552)

486 from Dr. Ronald G. Collman, pNL4-3 (cat\# 114) from Dr. Malcolm Martin, pREJO.c/2864 (cat\#

487 11746) and pCHO77.t/2626 (cat\# 11742) from Dr. John Kappes and Dr. Christina Ochsenbauer

488 and pYU2 (cat\# 1350) from Dr. Beatrice Hahn and Dr. George Shaw. pCDNA.3.hMR was

489 obtained from Dr. Johnny J. He (Liu, Liu et al. 2004). Vpr-null versions of HIV molecular clones

490 were created by cutting the Aflll site within $v p r$ and filling in with Klenow fragment. A nef-null

491 version of 89.6 was created by deleting nef from its start codon to the Xhol site. To do this, a PCR

492 amplicon was generated from the Xhol site in env to env's stop codon. The 3' reverse primer

493 added a Xhol site after the stop codon. The 89.6 genome and the amplicon were digested with

494 Xhol and ligated together. (5' primer CACCATTATCGTTTCAGACCCT and 3' primer

\section{TCTCGAGTTTAAACTTATAGCAAAGCCCTTTCCA)}

pSIV3+, pSPAX2, pAPPM-1221 were obtained from Dr. Jeremy Luban (Pertel, Reinhard et al. 2011). pSIV3+ vpr-null was generated using a synthesized fragment (ThermoFisher Scientific, Waltham, Massachusetts) of the SIV genome in which the Vpr start codon was converted to a stop codon. pYU2 env was obtained from Dr. Joseph Sodroski (Sullivan, Sun et al. 1995). Creation of pNL4-3 $\triangle$ GPE-GFP was described previously (McNamara, Ganesh et al. 2012).

Primary MDM and T cell isolation and culture

504 Leukocytes isolated from anonymous donors by apheresis were obtained from the New York 505 Blood Center Component Laboratory. The use of human blood from anonymous, de-identified 506 donors was classified as non-human subject research in accordance with federal regulations and 507 thus not subjected to formal IRB review. Peripheral blood mononuclear cells (PBMCs) were 508 purified by Ficoll density gradient. CD14 $4^{+}$monocytes were positively selected using a CD14 
sorting kit (StemCell Inc., Vancouver, Canada) following the manufacturer's instructions. Monocyte-derived macrophages (MDM) were obtained by culturing monocytes in R10 [RPMI-

5111640 with 10\% certified endotoxin-low fetal bovine serum (Invitrogen, ThermoFisher)], penicillin

512 (10 Units $/ \mathrm{ml})$, streptomycin $(10 \mu \mathrm{g} / \mathrm{ml})$, L-glutamine $(292 \mu \mathrm{g} / \mathrm{ml})$, carrier-free M-CSF $(50 \mathrm{ng} / \mathrm{ml}$,

513 R\&D Systems, Minneapolis, Minnesota) and GM-CSF (50 ng/ml, R\&D Systems) for seven days.

514 Monocytes were plated at $5 \times 10^{5}$ cells/well in a 24 well dish, except for those to be transduced 515 with lentivirus and puromycin selected, which were plated at $1 \times 10^{6}$ cells $/$ well.

$517 \mathrm{CD}^{+} \mathrm{T}$ lymphocytes were isolated from PBMCs by CD8 negative selection (DynaBeads, 518 ThermoFisher), cultured in R10 for several days and activated with $5 \mu \mathrm{g} / \mathrm{ml}$ phytohaemagglutinin 519 (PHA-L, Calbiochem, Millipore Sigma, Burlington, Massachusetts) overnight before addition of $520500 \mathrm{IU} / \mathrm{ml}$ recombinant human IL-2 (R\&D Systems).

\section{Silencing by shRNA}

523 Short hairpin RNA-mediated silencing was performed as previously described (Pertel, Reinhard 524 et al. 2011, Collins, Lubow et al. 2015). Briefly, we spinoculated freshly isolated primary 525 monocytes with VSV-G-pseudotyped SIV3+ vpr-null at $2500 \mathrm{rpm}$ for 2 hours with $4 \mu \mathrm{g} / \mathrm{ml}$ 526 polybrene to allow Vpx-dependent degradation of SAMHD1. Cells were then incubated overnight 527 in R10 with M-CSF (50 ng/ml) and GM-CSF (50 ng/ml) plus VSV-G-pseudotyped lentivirus 528 containing an shRNA cassette targeting luciferase (shNC) or MR (shMR). Following an overnight 529 incubation, the cells were cultured for 3 days in fresh medium before addition of $10 \mu \mathrm{g} / \mathrm{ml}$ 530 puromycin for 3 additional days prior to HIV-1 infection. shRNA target sequences 531 used: Luciferase: $\quad$ 5'-TACAAACGCTCTCATCGACAAG-3', MRC1: 5'532 ATTGATTATCAGTCAAGTTACT-3' 


\section{Virus production}

536 Virus stocks were obtained by transfecting HEK293T cells (ATCC, Manassas, Virginia) with viral

537 DNA and polyethylenimine (PEI). Cells were plated at $2.5 \times 10^{6}$ cells per $10 \mathrm{~cm}$ dish and incubated

538 overnight. The following day $12 \mu \mathrm{g}$ of total DNA was combined with $48 \mu \mathrm{g}$ of PEI, mixed by

539 vortexing, and added to each plate of cells. For NL4-3 $\Delta$ GPE-GFP cells were transfected with 4

$540 \mu \mathrm{g}$ viral genome, $4 \mu \mathrm{g}$ pCMV-HIV, and $4 \mu \mathrm{g}$ VSV-G plasmid. For SIV $3+\Delta \mathrm{Vpr}$ the cells were

541 transfected with $10.5 \mu \mathrm{g}$ of viral genome and $1.5 \mu \mathrm{g}$ VSV-G plasmid. Viral supernatant was

542 collected 48 hours post-transfection and centrifuged at $1500 \mathrm{rpm} 5 \mathrm{~min}$ to remove cellular debris.

543 SIV3 $+\Delta \mathrm{Vpr}$ was pelleted by centrifugation at $14,000 \mathrm{rpm}$ for 4 hours at $4^{\circ} \mathrm{C}$ and resuspended at

$54410 x$ concentration. Virus stocks were aliquoted and stored at $-80^{\circ} \mathrm{C}$.

\section{Co-transfections}

547 Co-transfections of HIV and MR were performed in HEK293T cells. Cells were plated at $1.6 \times 10^{5}$

548 per well in a 12-well dish. The following day $100 \mathrm{ng}$ of pcDNA.3.hMR, $250 \mathrm{ng}$ of NL4-3 $\Delta$ GPE-

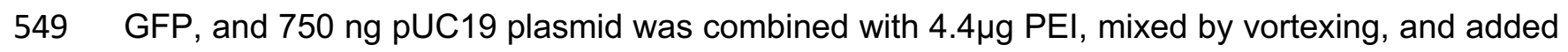

550 to each well. Cells were lifted using enzyme free cell dissociation buffer (ThermoFisher, cat \#

551 12151014) 48 hours later and analyzed by flow cytometry.

\section{HIV infections of MDM}

554 Prior to infection, $500 \mu \mathrm{L}$ of medium was removed from each well and this "conditioned" medium

555 was saved to be replaced after the infection. MDM were infected by equal inocula of HIV as

556 measured by Gag p24 mass in $500 \mu \mathrm{L}$ of R10 for 6 hours at $37^{\circ} \mathrm{C}$. After 6 hours, infection medium

557 was removed and replaced with a 1:2 mixture of conditioned medium and fresh R10. Where

558 indicated, HIV spread was blocked by AMD3100 (10 $\mu \mathrm{g} / \mathrm{mL}$, AIDS Reagent Program cat\# 8128)

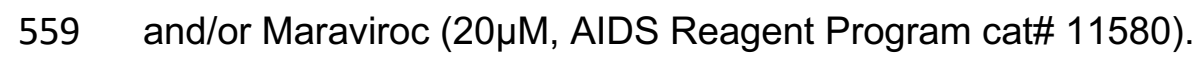




\section{Spin transduction of MDM with NL4-3 $\triangle$ GPE-GFP}

562 MDM were centrifuged at $2500 \mathrm{rpm}$ for 2 hours at $25^{\circ} \mathrm{C}$ with equal volume of NL4-3 $\Delta$ GPE-GFP

563 or an isogenic mutant in 500uL total medium. Following infection, medium was removed and

564 replaced with a 1:2 mixture of conditioned medium and fresh $\mathrm{R} 10$.

\section{Adenoviral transduction of MDM}

567 Adenovirus was prepared by the University of Michigan Vector Core, and the transduction of MDM

568 was performed as previously described (Leonard, Filzen et al. 2011) at an MOI of 1000 based on

569 HEK293T cell infection estimations and the concentration of particles as assessed by $\mathrm{OD}_{280}$.

\section{Infection of T cells}

572 Activated T cells were infected by three methods as indicated. For direct infection, $5 \times 10^{5}$ cells 573 were plated per well with $50 \mu \mathrm{g} \mathrm{HIV} \mathrm{p24} \mathrm{in} \mathrm{500 \mu L} \mathrm{R10}+100 \mathrm{IU} / \mathrm{mL}$ of IL-2 and incubated at $37^{\circ} \mathrm{C}$ 574 for 48 hours. For spin infection, $5 \times 10^{5}$ cells were plated per well with $50 \mu \mathrm{g}$ HIV and $4 \mathrm{ng} / \mathrm{mL}$ 575 polybrene in $500 \mu \mathrm{L} \mathrm{R} 10+100 \mathrm{IU} / \mathrm{mL}$ of IL-2 and centrifuged at $2500 \mathrm{rpm}$ for 2 hours at $25^{\circ} \mathrm{C}$. After 576 both types of infection, medium was removed and replaced with $1 \mathrm{~mL} R 10+100 \mathrm{IU} / \mathrm{mL}$ of IL-2. For 577 co-culture with autologous, infected MDM medium was removed from MDM wells and $5 \times 10^{5} \mathrm{~T}$ 578 cells were added in $1 \mathrm{~mL}$ R10 $+100 \mathrm{IU} / \mathrm{mL}$ of IL-2. All T cell infections were collected 48 hours post 579 infection.

\section{$581 \quad$ Flow cytometry}

582 Intracellular staining of cells using antibodies directed against HIV Gag p24 and MR was 583 performed by permeabilizing PFA-fixed cells with $0.1 \%$ Triton-X in PBS for 5 min, followed by 584 incubation with PE-conjugated antibody for 20 minutes at room temperature. Surface staining for 585 CD4, CD3 and CD14 was performed before fixation as described previously (Collins, Lubow et 586 al. 2015). Flow cytometric data was acquired using a FACSCanto instrument with FACSDiva 
587 collection software (BD, Franklin Lakes, New Jersey) or a FACScan (Cytek, BD) with FlowJo

588 software (TreeStar, Ashland, Oregon) and analyzed using FlowJo software. Live NL4-3 $\Delta$ GPE-

589 GFP transduced cells were sorted using a FACSAria III (BD) and gating on GFP ${ }^{+}$cells.

\section{Quantitative RT-PCR}

592 MDM sorted as described above in "Flow cytometry" were collected into tubes containing RLT 593 buffer (Qiagen, Hilden, Germany) and RNA was isolated using RNeasy Kit (Qiagen) with on594 column DNase I digestion. RNA was reverse transcribed using qScript cDNA SuperMix (Cat 595 \#95048, Quantabio, Beverly, Massachusetts). Quantitative PCR was performed using TaqMan 596 Gene Expression MasterMix (ThermoFisher, cat\# 4369016) on an Applied Biosystems 7300 Real597 Time PCR System using TaqMan Gene Expression primers with FAM-MGB probe. The primers 598 for ACTB are assay Hs99999903 and for MRC1 are assay Hs00267207 (ThermoFisher). 599 Reactions were quantified using $A B I$ Sequence Detection software compared to serial dilutions 600 of cDNA from mock-treated cells. Measured values for MRC1 were normalized to measured 601 values of $A C T B$.

\section{Immunoblot}

604 MDM cultures were lysed in Blue Loading Buffer (Cell Signaling Technologies, Danvers, 605 Massachusetts), sonicated with a Misonix sonicator (Qsonica, LLC., Newtown, Connecticut) and 606 clarified by centrifugation at 8000 RPM for 3 minutes. Lysates were analyzed by SDS-PAGE 607 immunoblot. The proteins MR, GAPDH and pr55 were visualized using AlexFluor-647 conjugated 608 secondary antibodies on a Typhoon FLA 9500 scanner (GE, Boston, Massachusetts) and 609 quantified using ImageQL (GE). The proteins gp160, gp120, gp41, Nef, Vpr and GFP were 610 visualized using HRP-conjugated secondary antibodies on film. Immunoblot films were scanned 611 and the mean intensity of each band, minus the background, was calculated using the histogram 612 function of Photoshop CC (Adobe, San Jose, California). 


\section{Virion Quantitation}

614 Supernatant containing viral particles was lysed in Triton X lysis buffer $(0.05 \%$ Tween $20,0.5 \%$

615 Triton X-100, 0.5\% casein in PBS). CAp24 antibody (clone 183-H12-5C) was bound to Nunc

616 MaxiSorp plates (ThermoFisher) at $4^{\circ} \mathrm{C}$ overnight. Lysed samples were captured for $2 \mathrm{hr}$ and then

617 incubated with biotinylated antibody to CAp24 (clone 31-90-25) for $1 \mathrm{hr}$. Clone 31-90-25 was

618 biotinylated with the EZ-Link Micro Sulfo-NHS-Biotinylation Kit (Pierce, ThermoFisher). Samples

619 were detected using streptavidin-HRP (Fitzgerald, Acton, Massachusetts) and 3,3',5,5'-

620 tetramethylbenzidine substrate. CAp24 concentrations were measured by comparison to

621 recombinant CAp24 standards (ViroGen, Watertown, Massachusetts).

\section{Antibodies}

624 Antibodies to CAp24 (clone KC57-PE, cat\# 6604667, Beckman Coulter, Brea, California), CD3

625 (clone OKT3-Pacific Blue, cat\# 317313, BioLegend, San Diego, California), CD14 (clone HCD14-

626 APC, cat\# 325608, BioLegend), CD4 (clone OKT4, cat\#17-0048-42, Invitrogen,

627 ThermoScientific), and MR (clone 19.2-PE, cat\# 555954, BD) were used for flow cytometry.

628 Antibodies to the following proteins were used for immunoblot analysis: MR (cat\# ab64693,

629 Abcam, Cambridge, Massachusetts), GAPDH (clone 3C2, cat\# H00002597-M01, Abnova, Taipei,

630 Taiwan), Gag pr55 (HIV-Ig AIDS Reagent Program cat\# 3957), Env gp160/120 (AIDS Reagent

631 Program Cat\# 288 from Dr. Michael Phelan) Env gp41 (AIDS Reagent Program cat\# 11557 from

632 Dr. Michael Zwick), Vpr (AIDS Reagent Program cat\# 3951 from Dr. Jeffrey Kopp). Neutralizing 633 antibody 2G12 (AIDS Reagent Program cat\# 1476 from Dr. Hermann Katinger) was used at a 1 $634 \mu \mathrm{g} / \mathrm{ml}$ for at the time of infection. 
bioRxiv preprint doi: https://doi.org/10.1101/742197; this version posted August 21, 2019. The copyright holder for this preprint (which was not certified by peer review) is the author/funder, who has granted bioRxiv a license to display the preprint in perpetuity. It is made available under aCC-BY 4.0 International license.

\section{Acknowledgments}

636 This research was supported by the NIH (5T32GM008353-27 to J.L., R01AI046998 to K.L.C., 637 R56Al130004 to K.L.C., R21AI32379 to K.L.C., T32GM007863 to M.M., T32AI007413 to M.M. 638 and T32AI007528 to D.R.C.). We are grateful to the University of Michigan Vector Core and the 639 NIH AIDS Reagent Program for reagents.

640

641 Competing Interests

642

643 No competing interests exist.

644

645 
Aiken, C., J. Konner, N. R. Landau, M. E. Lenburg and D. Trono (1994). "Nef induces CD4 endocytosis: requirement for a critical dileucine motif in the membrane-proximal CD4 cytoplasmic domain." Cell 76(5): 853-864.

651 Balliet, J. W., D. L. Kolson, G. Eiger, F. M. Kim, K. A. McGann, A. Srinivasan and R. 652 Collman (1994). "Distinct effects in primary macrophages and lymphocytes of the 653 human immunodeficiency virus type 1 accessory genes vpr, vpu, and nef: mutational 654 analysis of a primary HIV-1 isolate." Virology 200(2): 623-631.

Balzarini, J. (2007). "Targeting the glycans of glycoproteins: a novel paradigm for antiviral therapy." Nat Rev Microbiol 5(8): 583-597.

657 Belzile, J. P., G. Duisit, N. Rougeau, J. Mercier, A. Finzi and E. A. Cohen (2007). "HIV-1 658 Vpr-mediated G2 arrest involves the DDB1-CUL4AVPRBP E3 ubiquitin ligase." PLoS 659 Pathog 3(7): e85.

Bresnahan, P. A., W. Yonemoto, S. Ferrell, D. Williams-Herman, R. Geleziunas and W. C. Greene (1998). "A dileucine motif in HIV-1 Nef acts as an internalization signal for CD4 downregulation and binds the AP-1 clathrin adaptor." Curr Biol 8(22): 1235-1238.

663 Caldwell, R. L., B. S. Egan and V. L. Shepherd (2000). "HIV-1 Tat represses

664 transcription from the mannose receptor promoter." J Immunol 165(12): 7035-7041.

665

666

667

668

669

670

671

672

673

674

675

676

677

678

679

680

681
Chen, B. K., R. T. Gandhi and D. Baltimore (1996). "CD4 down-modulation during infection of human $T$ cells with human immunodeficiency virus type 1 involves independent activities of vpu, env, and nef." J Virol 70(9): 6044-6053.

Cluet, D., C. Bertsch, C. Beyer, L. Gloeckler, M. Erhardt, J. P. Gut, J. L. Galzi and A. M. Aubertin (2005). "Detection of human immunodeficiency virus type 1 Nef and CD4 physical interaction in living human cells by using bioluminescence resonance energy transfer." J Virol 79(13): 8629-8636.

Cohen, E. A., G. Dehni, J. G. Sodroski and W. A. Haseltine (1990). "Human immunodeficiency virus vpr product is a virion-associated regulatory protein." $\mathrm{J}$ Virol 64(6): 3097-3099.

Collins, D. R., J. Lubow, Z. Lukic, M. Mashiba and K. L. Collins (2015). "Vpr Promotes Macrophage-Dependent HIV-1 Infection of CD4+ T Lymphocytes." PLoS Pathog 11(7): e1005054.

Collman, R., J. W. Balliet, S. A. Gregory, H. Friedman, D. L. Kolson, N. Nathanson and A. Srinivasan (1992). "An infectious molecular clone of an unusual macrophage-tropic and highly cytopathic strain of human immunodeficiency virus type 1." J Virol 66(12): 7517-7521. 
682
Connor, R. I., B. K. Chen, S. Choe and N. R. Landau (1995). "Vpr is required for efficient replication of human immunodeficiency virus type-1 in mononuclear phagocytes." Virology 206(2): 935-944.

Coss, K. P., S. Vasiljevic, L. K. Pritchard, S. A. Krumm, M. Glaze, S. Madzorera, P. L. Moore, M. Crispin and K. J. Doores (2016). "HIV-1 Glycan Density Drives the Persistence of the Mannose Patch within an Infected Individual." J Virol 90(24): 1113211144.

Eckstein, D. A., M. P. Sherman, M. L. Penn, P. S. Chin, C. M. De Noronha, W. C. Greene and M. A. Goldsmith (2001). "HIV-1 Vpr enhances viral burden by facilitating infection of tissue macrophages but not nondividing CD4+ T cells." J Exp Med 194(10): 1407-1419.

Fanibunda, S. E., S. M. Velhal, V. P. Raghavan and A. H. Bandivdekar (2008). "CD4 independent binding of HIV gp120 to mannose receptor on human spermatozoa." $\underline{\mathrm{J}}$ Acquir Immune Defic Syndr 48(4): 389-397.

Greenberg, M., L. DeTulleo, I. Rapoport, J. Skowronski and T. Kirchhausen (1998). "A dileucine motif in HIV-1 Nef is essential for sorting into clathrin-coated pits and for downregulation of CD4." Curr Biol 8(22): 1239-1242.

Harris, R. S., J. F. Hultquist and D. T. Evans (2012). "The restriction factors of human immunodeficiency virus." J Biol Chem 287(49): 40875-40883.

Hoch, J., S. M. Lang, M. Weeger, C. Stahl-Hennig, C. Coulibaly, U. Dittmer, G. Hunsmann, D. Fuchs, J. Muller, S. Sopper and et al. (1995). "vpr deletion mutant of

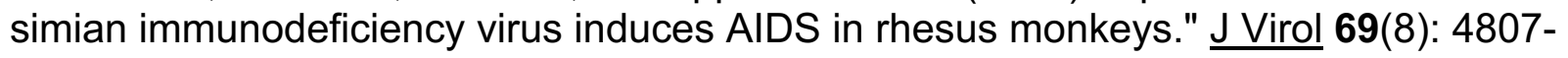
4813.

Holder, G. E., C. M. McGary, E. M. Johnson, R. Zheng, V. T. John, C. Sugimoto, M. J. Kuroda and W. K. Kim (2014). "Expression of the mannose receptor CD206 in HIV and SIV encephalitis: a phenotypic switch of brain perivascular macrophages with virus infection." J Neuroimmune Pharmacol 9(5): 716-726.

Hrecka, K., M. Gierszewska, S. Srivastava, L. Kozaczkiewicz, S. K. Swanson, L. Florens, M. P. Washburn and J. Skowronski (2007). "Lentiviral Vpr usurps Cul4DDB1[VprBP] E3 ubiquitin ligase to modulate cell cycle." Proc Natl Acad Sci U S A 104(28): 11778-11783.

Huang, J., B. H. Kang, M. Pancera, J. H. Lee, T. Tong, Y. Feng, H. Imamichi, I. S. Georgiev, G. Y. Chuang, A. Druz, N. A. Doria-Rose, L. Laub, K. Sliepen, M. J. van Gils, A. T. de la Pena, R. Derking, P. J. Klasse, S. A. Migueles, R. T. Bailer, M. Alam, P. Pugach, B. F. Haynes, R. T. Wyatt, R. W. Sanders, J. M. Binley, A. B. Ward, J. R. Mascola, P. D. Kwong and M. Connors (2014). "Broad and potent HIV-1 neutralization by a human antibody that binds the gp41-gp120 interface." Nature 515(7525): 138-142. 
Iyer, S. S., F. Bibollet-Ruche, S. Sherrill-Mix, G. H. Learn, L. Plenderleith, A. G. Smith, H. J. Barbian, R. M. Russell, M. V. Gondim, C. Y. Bahari, C. M. Shaw, Y. Li, T. Decker, B. F. Haynes, G. M. Shaw, P. M. Sharp, P. Borrow and B. H. Hahn (2017). "Resistance to type 1 interferons is a major determinant of HIV-1 transmission fitness." Proc Natl Acad Sci U S A 114(4): E590-E599.

Koziel, H., Q. Eichbaum, B. A. Kruskal, P. Pinkston, R. A. Rogers, M. Y. Armstrong, F. F. Richards, R. M. Rose and R. A. Ezekowitz (1998). "Reduced binding and phagocytosis of Pneumocystis carinii by alveolar macrophages from persons infected with HIV-1 correlates with mannose receptor downregulation." J Clin Invest 102(7): $1332-1344$.

Koziel, H., B. A. Kruskal, R. A. Ezekowitz and R. M. Rose (1993). "HIV impairs alveolar macrophage mannose receptor function against Pneumocystis carinii." Chest 103 (2 Suppl): 111S-112S.

732 Laguette, N., C. Bregnard, P. Hue, J. Basbous, A. Yatim, M. Larroque, F. Kirchhoff, A. 733 Constantinou, B. Sobhian and M. Benkirane (2014). "Premature activation of the SLX4 complex by $\mathrm{Vpr}$ promotes $\mathrm{G} 2 / \mathrm{M}$ arrest and escape from innate immune sensing." Cell 156(1-2): 134-145.

Lahouassa, H., M. L. Blondot, L. Chauveau, G. Chougui, M. Morel, M. Leduc, F. Guillonneau, B. C. Ramirez, O. Schwartz and F. Margottin-Goguet (2016). "HIV-1 Vpr USA 113(19): 5311-5316. (2009). "Oligomerization of the macrophage mannose receptor enhances gp120mediated binding of HIV-1." J Biol Chem 284(17): 11027-11038. reduces HIV-1 infectivity by blocking Env incorporation in a Nef- and Vpu-inhibitable manner." Curr Biol 9(12): 622-631. Margottin-Goguet (2007). "HIV1 Vpr arrests the cell cycle by recruiting DCAF1/VprBP, a receptor of the Cul4-DDB1 ubiquitin ligase." Cell Cycle 6(2): 182-188. (1990). "Assignment of intrachain disulfide bonds and characterization of potential glycosylation sites of the type 1 recombinant human immunodeficiency virus envelope 753 10373-10382. and CD28 by distinct pathways that share common elements." J Virol 85(14): 68676881. 
Li, Y., J. C. Kappes, J. A. Conway, R. W. Price, G. M. Shaw and B. H. Hahn (1991). "Molecular characterization of human immunodeficiency virus type 1 cloned directly from uncultured human brain tissue: identification of replication-competent and defective viral genomes." J Virol 65(8): 3973-3985.

Liang, W. W., X. Shi, D. Deshpande, C. J. Malanga and Y. Rojanasakul (1996). "Oligonucleotide targeting to alveolar macrophages by mannose receptor-mediated endocytosis." Biochim Biophys Acta 1279(2): 227-234.

Liao, F., R. L. Rabin, C. S. Smith, G. Sharma, T. B. Nutman and J. M. Farber (1999). "CC-chemokine receptor 6 is expressed on diverse memory subsets of T cells and determines responsiveness to macrophage inflammatory protein 3 alpha." $\mathrm{J}$ Immunol 162(1): 186-194.

Linehan, S. A., L. Martinez-Pomares, P. D. Stahl and S. Gordon (1999). "Mannose receptor and its putative ligands in normal murine lymphoid and nonlymphoid organs: In situ expression of mannose receptor by selected macrophages, endothelial cells, perivascular microglia, and mesangial cells, but not dendritic cells." J Exp Med 189(12): 1961-1972.

Liu, Y., H. Liu, B. O. Kim, V. H. Gattone, J. Li, A. Nath, J. Blum and J. J. He (2004). "CD4-independent infection of astrocytes by human immunodeficiency virus type 1: requirement for the human mannose receptor." J Virol 78(8): 4120-4133.

Lu, Y. L., P. Spearman and L. Ratner (1993). "Human immunodeficiency virus type 1 viral protein R localization in infected cells and virions." J Virol 67(11): 6542-6550.

Macedo-Ramos, H., A. F. Batista, A. Carrier-Ruiz, L. Alves, S. Allodi, V. T. RibeiroResende, L. M. Teixeira and W. Baetas-da-Cruz (2014). "Evidence of involvement of the mannose receptor in the internalization of Streptococcus pneumoniae by Schwann cells." BMC Microbiol 14: 211.

Mashiba, M., D. R. Collins, V. H. Terry and K. L. Collins (2014). "Vpr overcomes macrophage-specific restriction of HIV-1 Env expression and virion production." Cell Host Microbe 16(6): 722-735.

Mashiba, M. and K. L. Collins (2013). "Molecular mechanisms of HIV immune evasion of the innate immune response in myeloid cells." Viruses 5(1): 1-14.

McCall, C. M., P. L. Miliani de Marval, P. D. Chastain, 2nd, S. C. Jackson, Y. J. He, Y. Kotake, J. G. Cook and Y. Xiong (2008). "Human immunodeficiency virus type $1 \mathrm{Vpr}-$ binding protein VprBP, a WD40 protein associated with the DDB1-CUL4 E3 ubiquitin ligase, is essential for DNA replication and embryonic development." Mol Cell Biol 28(18): 5621-5633.

McGreal, E. P., M. Rosas, G. D. Brown, S. Zamze, S. Y. Wong, S. Gordon, L. MartinezPomares and P. R. Taylor (2006). "The carbohydrate-recognition domain of Dectin-2 is a C-type lectin with specificity for high mannose." Glycobiology 16(5): 422-430. 
McNamara, L. A., J. A. Ganesh and K. L. Collins (2012). "Latent HIV-1 infection occurs in multiple subsets of hematopoietic progenitor cells and is reversed by NF-kappaB activation." J Virol 86(17): 9337-9350.

Michel, N., I. Allespach, S. Venzke, O. T. Fackler and O. T. Keppler (2005). "The Nef protein of human immunodeficiency virus establishes superinfection immunity by a dual strategy to downregulate cell-surface CCR5 and CD4." Curr Biol 15(8): 714-723.

Michel, N., K. Ganter, S. Venzke, J. Bitzegeio, O. T. Fackler and O. T. Keppler (2006). "The Nef protein of human immunodeficiency virus is a broad-spectrum modulator of chemokine receptor cell surface levels that acts independently of classical motifs for receptor endocytosis and Galphai signaling." Mol Biol Cell 17(8): 3578-3590.

Nguyen, D. G. and J. E. Hildreth (2003). "Involvement of macrophage mannose receptor in the binding and transmission of HIV by macrophages." Eur J Immunol 33(2): 483-493.

Ochsenbauer, C., T. G. Edmonds, H. Ding, B. F. Keele, J. Decker, M. G. Salazar, J. F. Salazar-Gonzalez, R. Shattock, B. F. Haynes, G. M. Shaw, B. H. Hahn and J. C. Kappes (2012). "Generation of transmitted/founder HIV-1 infectious molecular clones and characterization of their replication capacity in CD4 T lymphocytes and monocytederived macrophages." J Virol 86(5): 2715-2728.

Pertel, T., C. Reinhard and J. Luban (2011). "Vpx rescues HIV-1 transduction of dendritic cells from the antiviral state established by type 1 interferon." Retrovirology 8: 49.

Peters, P. J., M. P. Gonzalez-Perez, T. Musich, T. A. Moore Simas, R. Lin, A. N. Morse, R. J. Shattock, C. A. Derdeyn and P. R. Clapham (2015). "Infection of ectocervical tissue and universal targeting of T-cells mediated by primary non-macrophage-tropic and highly macrophage-tropic HIV-1 R5 envelopes." Retrovirology 12: 48.

Pritchard, L. K., D. I. Spencer, L. Royle, C. Bonomelli, G. E. Seabright, A. J. Behrens, D. W. Kulp, S. Menis, S. A. Krumm, D. C. Dunlop, D. J. Crispin, T. A. Bowden, C. N. Scanlan, A. B. Ward, W. R. Schief, K. J. Doores and M. Crispin (2015). "Glycan clustering stabilizes the mannose patch of HIV-1 and preserves vulnerability to broadly neutralizing antibodies." Nat Commun 6: 7479.

Reading, C. L., E. E. Penhoet and C. E. Ballou (1978). "Carbohydrate structure of vesicular stomatitis virus glycoprotein." J Biol Chem 253(16): 5600-5612.

Ross, T. M., A. E. Oran and B. R. Cullen (1999). "Inhibition of HIV-1 progeny virion release by cell-surface CD4 is relieved by expression of the viral Nef protein." Curr Biol 9(12): 613-621.

Rucker, E., J. C. Grivel, J. Munch, F. Kirchhoff and L. Margolis (2004). "Vpr and Vpu are important for efficient human immunodeficiency virus type 1 replication and CD4+ T-cell depletion in human lymphoid tissue ex vivo." J Virol 78(22): 12689-12693. 
Sanders, R. W., M. Venturi, L. Schiffner, R. Kalyanaraman, H. Katinger, K. O. Lloyd, P. D. Kwong and J. P. Moore (2002). "The mannose-dependent epitope for neutralizing antibody 2G12 on human immunodeficiency virus type 1 glycoprotein gp120." J Virol 76(14): 7293-7305.

Scanlan, C. N., R. Pantophlet, M. R. Wormald, E. Ollmann Saphire, R. Stanfield, I. A. Wilson, H. Katinger, R. A. Dwek, P. M. Rudd and D. R. Burton (2002). "The broadly neutralizing anti-human immunodeficiency virus type 1 antibody $2 \mathrm{G} 12$ recognizes a cluster of alpha1-->2 mannose residues on the outer face of gp120." J Virol 76(14): 7306-7321.

Schrofelbauer, B., Y. Hakata and N. R. Landau (2007). "HIV-1 Vpr function is mediated by interaction with the damage-specific DNA-binding protein DDB1." Proc Natl Acad Sci U S A 104(10): 4130-4135. immunodeficiency virus type $1 \mathrm{Vpr}$ induces the degradation of the UNG and SMUG uracil-DNA glycosylases." J Virol 79(17): 10978-10987. Walters, S. Dandekar, P. R. Clapham, L. E. Smythies and P. D. Smith (2009). "Macrophages in vaginal but not intestinal mucosa are monocyte-like and permissive to human immunodeficiency virus type 1 infection." J Virol 83(7): 3258-3267.

Shibata, Y., W. J. Metzger and Q. N. Myrvik (1997). "Chitin particle-induced cellmediated immunity is inhibited by soluble mannan: mannose receptor-mediated phagocytosis initiates IL-12 production." J Immunol 159(5): 2462-2467.

Stahl, P., P. H. Schlesinger, E. Sigardson, J. S. Rodman and Y. C. Lee (1980). "Receptor-mediated pinocytosis of mannose glycoconjugates by macrophages: characterization and evidence for receptor recycling." Cell 19(1): 207-215.

Stahl, P. D. and R. A. Ezekowitz (1998). "The mannose receptor is a pattern recognition receptor involved in host defense." Curr Opin Immunol 10(1): 50-55.

Stewart-Jones, G. B., C. Soto, T. Lemmin, G. Y. Chuang, A. Druz, R. Kong, P. V. Thomas, K. Wagh, T. Zhou, A. J. Behrens, T. Bylund, C. W. Choi, J. R. Davison, I. S. Georgiev, M. G. Joyce, Y. D. Kwon, M. Pancera, J. Taft, Y. Yang, B. Zhang, S. S. Shivatare, V. S. Shivatare, C. C. Lee, C. Y. Wu, C. A. Bewley, D. R. Burton, W. C. Koff, M. Connors, M. Crispin, U. Baxa, B. T. Korber, C. H. Wong, J. R. Mascola and P. D. Kwong (2016). "Trimeric HIV-1-Env Structures Define Glycan Shields from Clades A, B, and G." Cell 165(4): 813-826. Plant, A. Kadioglu and B. Henriques-Normark (2019). "Pneumolysin binds to the mannose receptor $C$ type 1 (MRC-1) leading to anti-inflammatory responses and enhanced pneumococcal survival." Nat Microbiol 4(1): 62-70. 
873 Sukegawa, S., E. Miyagi, F. Bouamr, H. Farkasova and K. Strebel (2018). "Mannose

874 Receptor 1 Restricts HIV Particle Release from Infected Macrophages." Cell Rep 22(3):

875 786-795.

876 Sullivan, N., Y. Sun, J. Li, W. Hofmann and J. Sodroski (1995). "Replicative function and 877 neutralization sensitivity of envelope glycoproteins from primary and T-cell line-

878 passaged human immunodeficiency virus type 1 isolates." J Virol 69(7): 4413-4422.

879 Trkola, A., M. Purtscher, T. Muster, C. Ballaun, A. Buchacher, N. Sullivan, K.

880 Srinivasan, J. Sodroski, J. P. Moore and H. Katinger (1996). "Human monoclonal 881 antibody 2G12 defines a distinctive neutralization epitope on the gp120 glycoprotein of 882 human immunodeficiency virus type 1." J Virol 70(2): 1100-1108.

883 Trujillo, J. R., R. Rogers, R. M. Molina, F. Dangond, M. F. McLane, M. Essex and J. D. 884 Brain (2007). "Noninfectious entry of HIV-1 into peripheral and brain macrophages 885 mediated by the mannose receptor." Proc Natl Acad Sci U S A 104(12): 5097-5102.

Venzke, S., N. Michel, I. Allespach, O. T. Fackler and O. T. Keppler (2006). "Expression of Nef downregulates CXCR4, the major coreceptor of human immunodeficiency virus, from the surfaces of target cells and thereby enhances resistance to superinfection." $\underline{\mathrm{J}}$ Virol 80(22): 11141-11152.

890 Vigerust, D. J., B. S. Egan and V. L. Shepherd (2005). "HIV-1 Nef mediates post891 translational down-regulation and redistribution of the mannose receptor." J Leukoc Biol 892 77(4): 522-534.

893 Wen, X., K. M. Duus, T. D. Friedrich and C. M. de Noronha (2007). "The HIV1 protein 894 Vpr acts to promote G2 cell cycle arrest by engaging a DDB1 and Cullin4A-containing 895 ubiquitin ligase complex using VprBP/DCAF1 as an adaptor." J Biol Chem 282(37): 896 27046-27057.

897 Wu, Y., X. Zhou, C. O. Barnes, M. Delucia, A. E. Cohen, A. M. Gronenborn, J. Ahn and 898 G. Calero (2016). "The DDB1-DCAF1-Vpr-UNG2 crystal structure reveals how HIV-1 899 Vpr steers human UNG2 toward destruction." Nat Struct Mol Biol 23(10): 933-940.

900 Zhou, X., M. DeLucia and J. Ahn (2016). "SLX4-SLX1 Protein-independent Down901 regulation of MUS81-EME1 Protein by HIV-1 Viral Protein R (Vpr)." J Biol Chem 902 291(33): 16936-16947.

903

904 
A

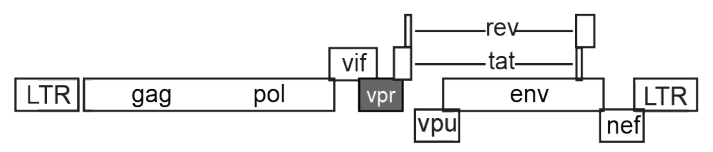

B

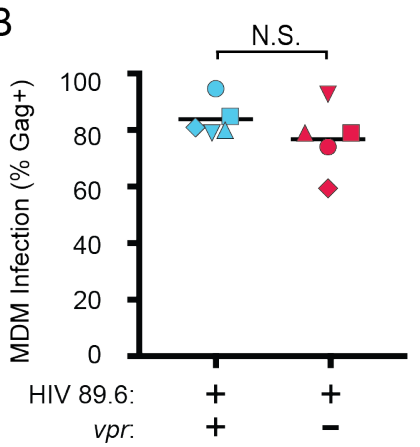

E

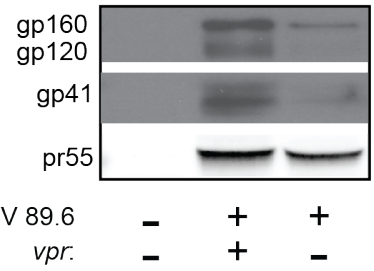

C

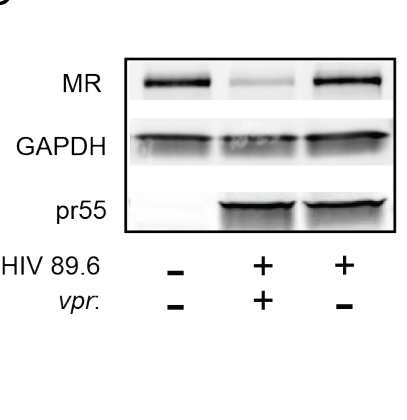

D
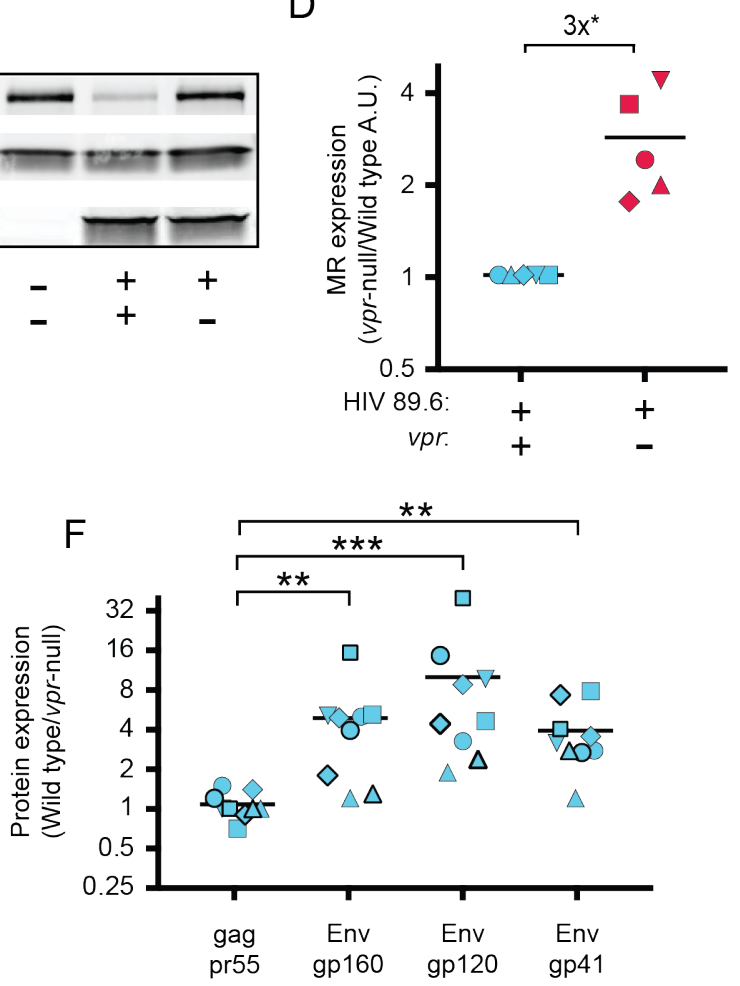

Figure 1: HIV Vpr reduces steady state levels of host mannose receptor in MDM and increases steady state levels of viral Env protein. A) Diagram of the HIV 89.6 proviral genome. The shaded box shows the location of $v p r$, which was disrupted by a frame shift mutation to create the Vpr-null version (Mashiba, Collins et al. 2014). HIV189.6 is a dual CXCR4/CCR5-tropic HIV molecular clone isolated from the peripheral blood of an AIDS patient (Collman, Balliet et al. 1992). B) Summary graph depicting MDM infected by HIV 89.6 wild type and vpr-null with matched infection frequencies of at least $50 \% 10$ days post infection as measured flow cytometrically by intracellular Gag p24 staining. This subset with high frequencies of infection was selected to examine potential effects on host factors. Statistical significance was determined using a two-tailed, paired $t$-test. N.S. - not significant, $p=0.34 \mathrm{C}$ ) Western blot analysis of whole cell lysates from MDM prepared as in B. D) Summary graph displaying relative expression of MR in wild type and mutant 89.6 from blots as shown in B. Western blot protein bands were quantified using a Typhoon scanner. Values for MR expression in MDM infected with Vpr-null HIV were normalized to GAPDH and then to wild type for each donor. Statistical significance was determined using a two-tailed, paired $t$-test. * $p=0.03 \mathrm{E}$ ) Western blot analysis of HIV protein expression in MDM infected as in B. F) Summary graph of HIV protein expression from western blot analysis as in $E$ and quantified as described in methods. The ratio of expression in wild type to vpr-null infection is shown. Data from 9 independent donors with similar frequencies of infection (within 2-fold) following ten days of infection are shown. Statistical significance was determined using a two-tailed, ratio $t$-test, ${ }^{* *} p<0.01,{ }^{* * *} p<0.001$. Data from each donor is represented by the same symbol in all charts. Mean values are indicated. 
bioRxiv preprint doi: https://doi.org/10.1101/742197; this version posted August 21,2019 . The copyright holder for this preprint (which was not certified by peer review) is the author/funder, who has granted bioRxiv a license to display the preprint in perpetuity. It is made available under aCC-BY 4.0 International license.

A

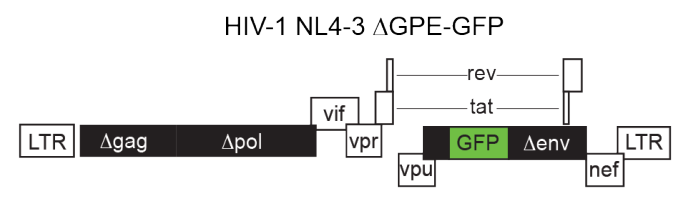

C
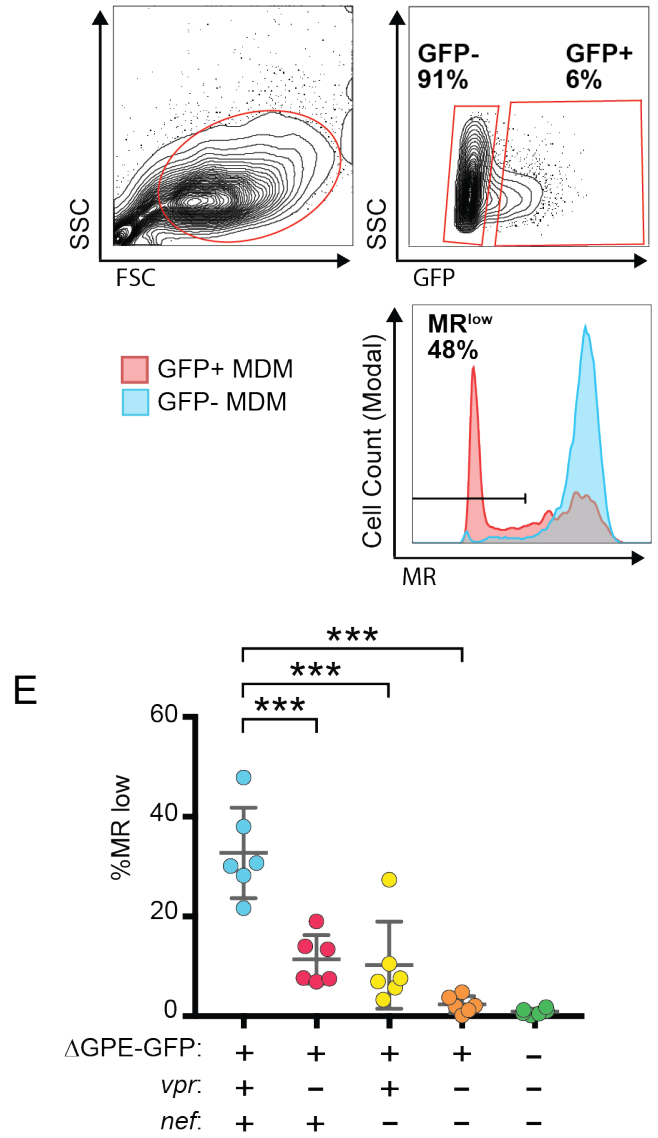

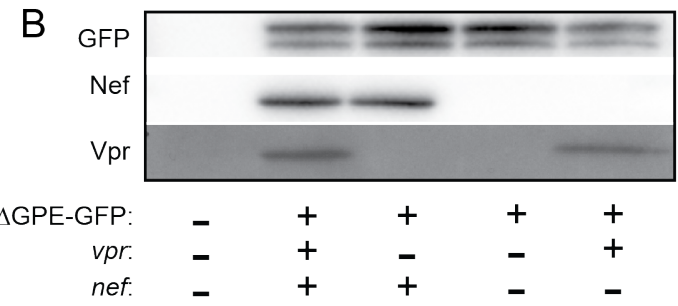

D

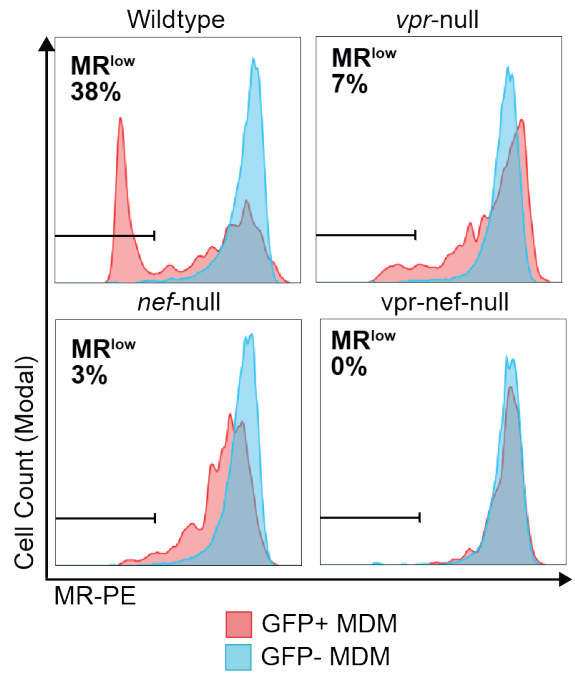

$\mathrm{F}$

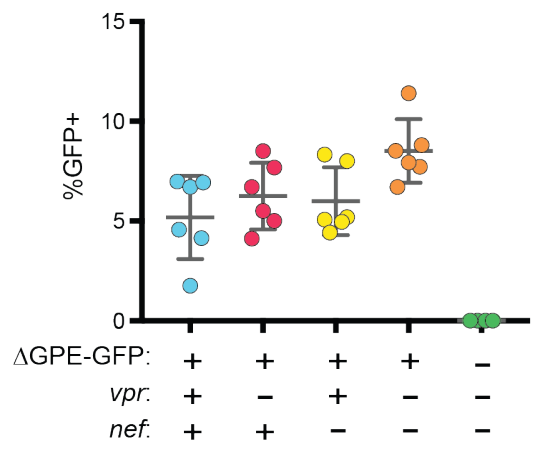

G

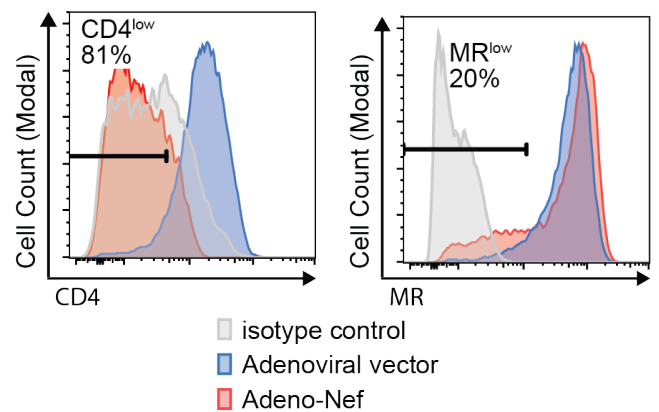

$\mathrm{H}$

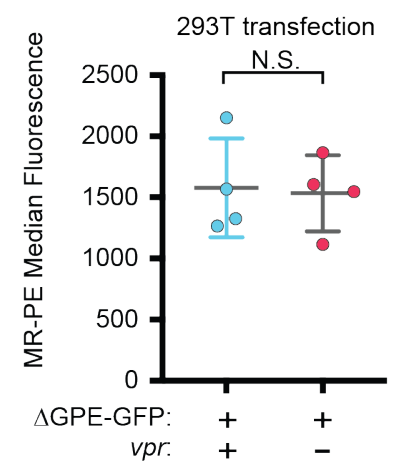

I

MDM transduction

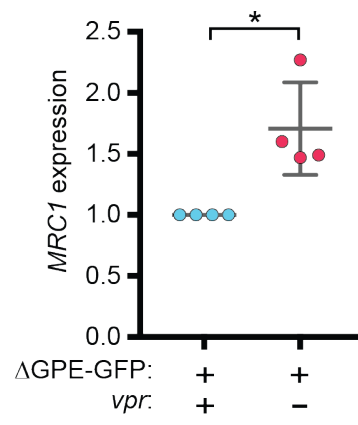

Figure 2: Combined effects of Nef and Vpr completely remove MR from a significant proportion of infected cells at early time points. A) Diagram of HIV NL4-3 $\triangle$ GPE-GFP. B) Western blot analysis of whole cell lysates from HEK293T cells transfected with the indicated viral expression construct. C) The gating strategy used to identify live GFP ${ }^{+}$vs GFP- cells and the fraction of cells that are MR ${ }^{\text {low }}$. D) Representative flow cytometric analysis of MDM at five days post transduction by the indicated virus. The percentage of $\mathrm{GFP}^{+}$cells that fell into the $\mathrm{MR}^{\text {low }}$ gate is indicated in each panel. E) Summary graph depicting the percentage of $\mathrm{GFP}^{+}$cells that fell into the MR ${ }^{\text {low }}$ gate in transduced MDM. For the uninfected column the GFP- cells are displayed. ( $n=6$ independent donors) F) Summary graph depicting the frequency of transduced $\left(\mathrm{GFP}^{+}\right) \mathrm{MDM}$ at the time of harvest. G) Representative flow cytometric plots of MDM transduced with the indicated adenoviral vector ( $n=3$ independent donors). H) Summary graph of MR 
bioRxiv preprint doi: https://doi.org/10.1101/742197; this version posted August 21, 2019. The copyright holder for this preprint (which was not certified by peer review) is the author/funder, who has granted bioRxiv a license to display the preprint in perpetuity. It is made available under aCC-BY 4.0 International license.

935 levels as measured by flow cytometry in HEK293T cells co-transfected with the indicated HIV construct. Transfected $\left(\mathrm{GFP}^{+}\right)$cells were identified using the gating strategy shown in Figure S1. ( $n=$ four independent transfections) I) Summary graph of mannose receptor (MRC1) mRNA expression in MDM transduced with the indicated HIV reporter and sorted for GFP expression by FACS. Expression of MRC1 was measured by qRT-PCR and normalized to ACTB and to the wild type transduction. ( $n=4$ independent donors). Mean $+/-$ standard deviation is shown. Statistical significance was determined by a two-tailed, paired $t$-test. N.S. not significant: $p=0.89,{ }^{*} p=0.03,{ }^{* *} p<0.001$, 
bioRxiv preprint doi: https://doi.org/10.1101/742197; this version posted August 21,2019 . The copyright holder for this preprint (which was not certified by peer review) is the author/funder, who has granted bioRxiv a license to display the preprint in perpetuity. It is made available under

A

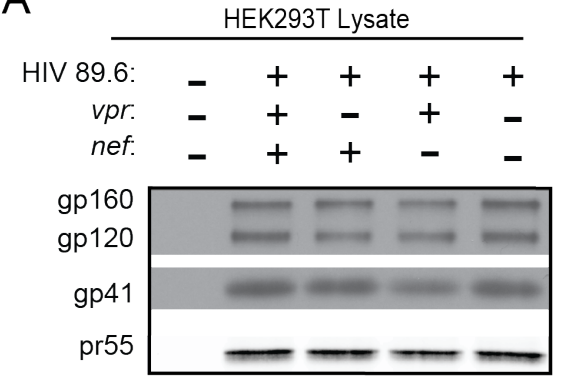

C

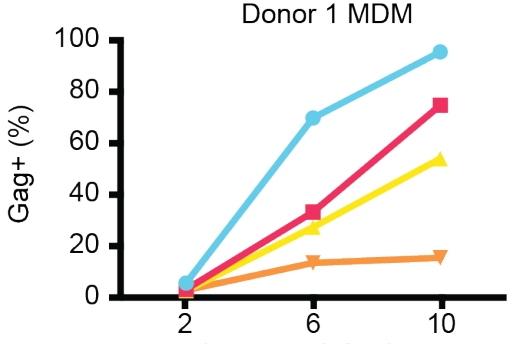

days post infection
B

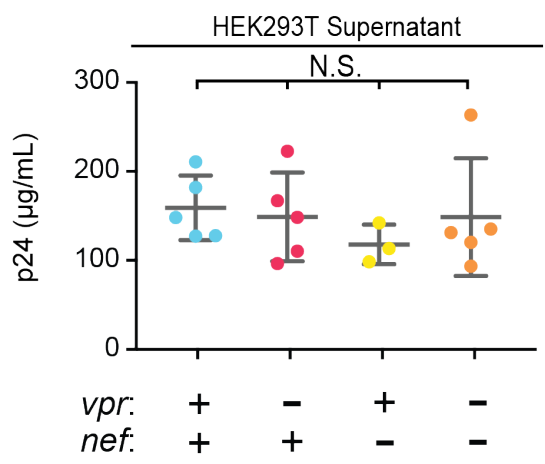

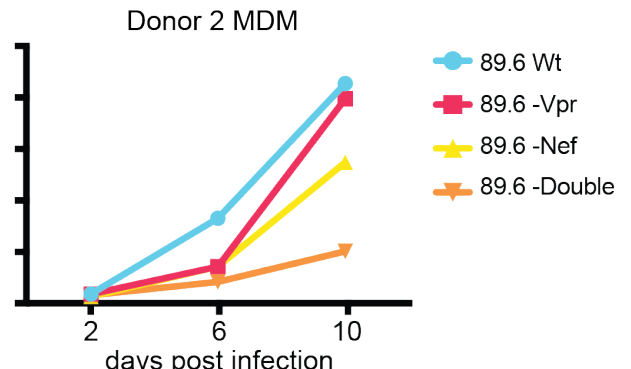

MDM Supernatant
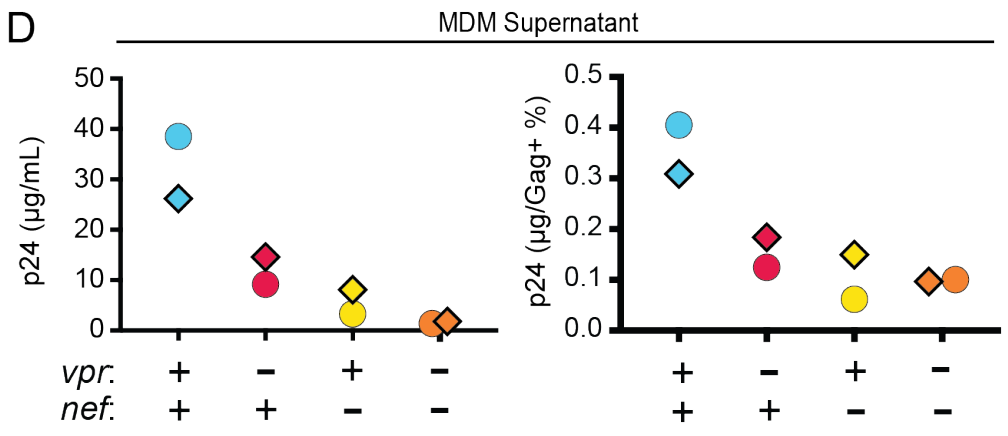

E $\checkmark$ Donor 1

- Donor 2

Figure 3: Combined effect of Vpr and Nef dramatically enhances Env levels in primary human MDM. A) Western blot analysis of whole cell lysate from HEK293T transfected with the the indicated HIV construct. B) Summary graph of virion release from HEK293Ts transfected as in A as measured by Gag p24 ELISA. ( $n=5$ independent transfections). The mean $+/$ - standard deviation is shown. Statistical significance was determined by one-way ANOVA. (N.S. - not significant) C) Frequency of infected primary human MDM infected with the indicated HIV and analyzed over time by flow cytometric analysis of intracellular Gag. (For parts C-E, $n=$ 2 independent donors). D) Virion release by primary human MDM infected with the indicated HIV and analyzed by Gag p24 ELISA 10 days post infection. In the right panel, virion release was adjusted for frequency of infected cells as measured in part C. E) Western blot analysis of whole cell lysate from primary human MDM infected with the indicated HIV. Lanes $2-6$ are a serial dilution series of the wild type sample. The arrows below the Gag pr55 
bioRxiv preprint doi: https://doi.org/10.1101/742197; this version posted August 21,2019 . The copyright holder for this preprint (which was not certified by peer review) is the author/funder, who has granted bioRxiv a license to display the preprint in perpetuity. It is made available under aCC-BY 4.0 International license.

955 bands indicate the dilution (4 fold) of wild type that has approximately the same amount of Gag pr55 as the vpr956 nef-null double mutant.

957 
bioRxiv preprint doi: https://doi.org/10.1101/742197; this version posted August 21,2019 . The copyright holder for this preprint (which was not certified by peer review) is the author/funder, who has granted bioRxiv a license to display the preprint in perpetuity. It is made available under aCC-BY 4.0 International license.

A

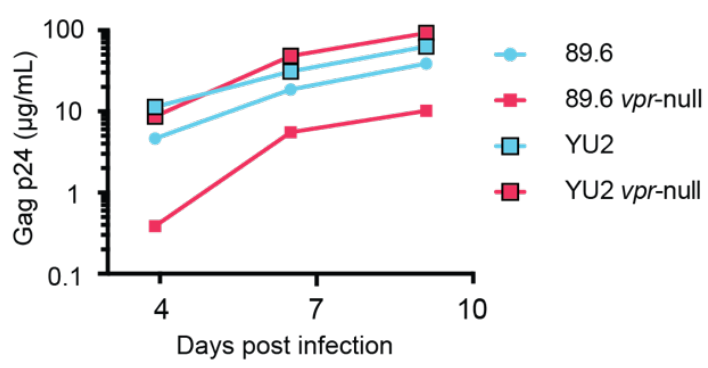

C

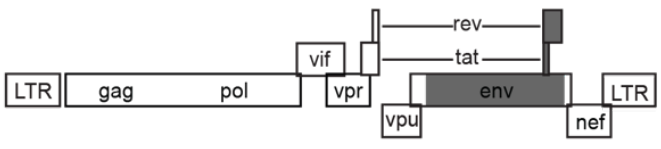

$E$

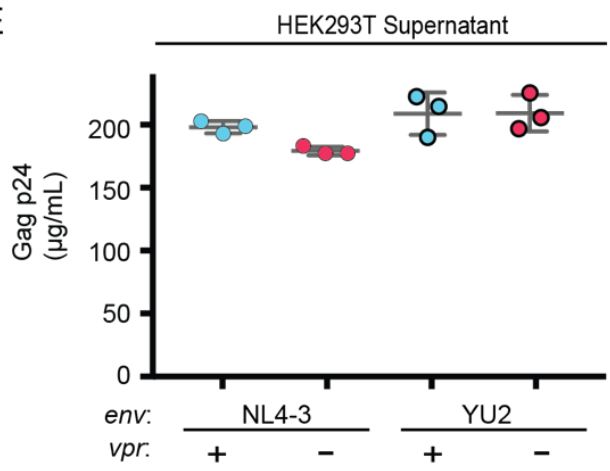

G

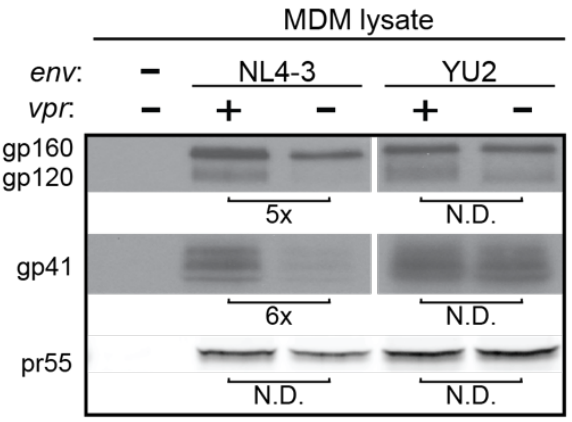

B

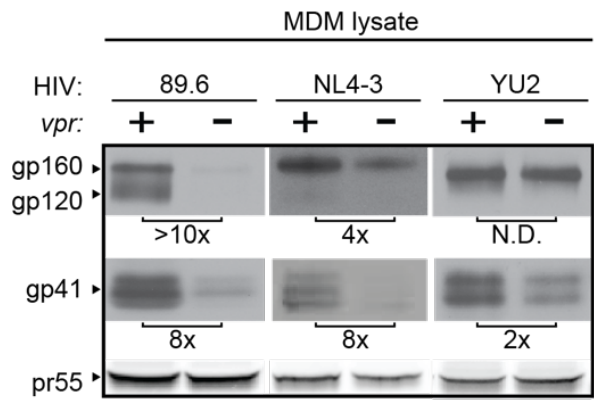

D
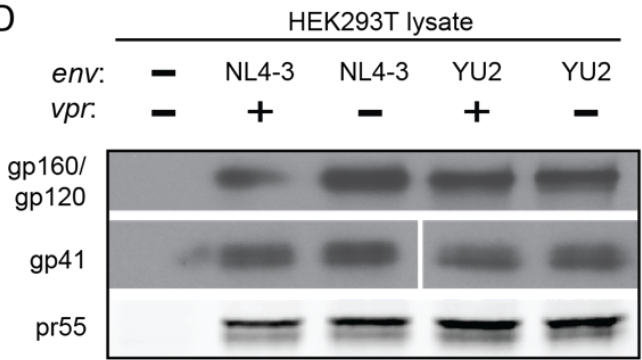

$\mathrm{F}$

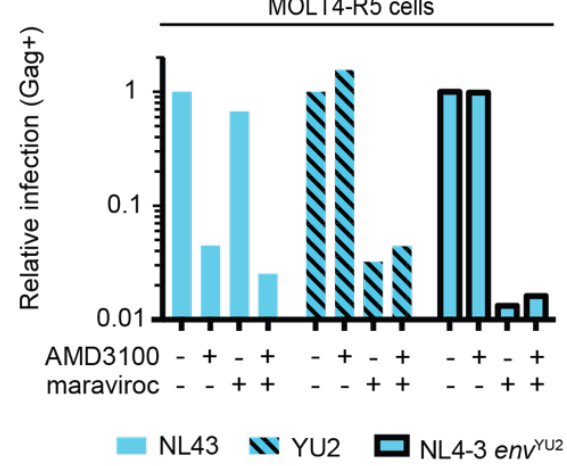

$\mathrm{H}$

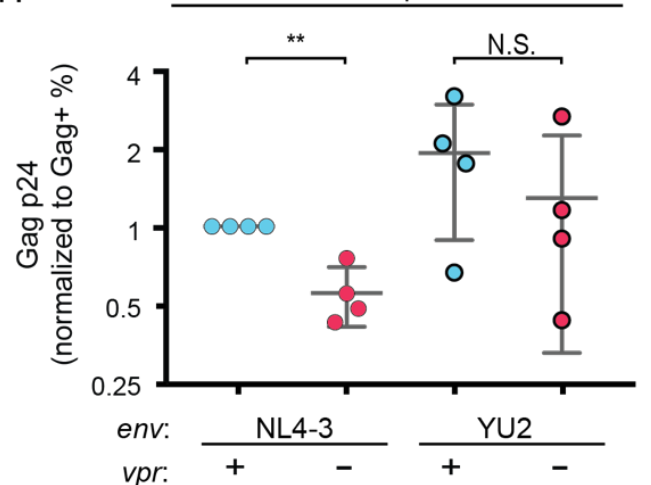

Figure 4: HIV YU2, which lacks a mannose rich patch, does not require Vpr for robust Env protein expression and spread in MDM. A) Virion release over time by primary human MDM infected with the indicated HIV as measured by ELISA ( $n=2$ independent donors). B) Western blot analysis of whole cell lysate from MDM infected for 10 days with the indicated HIV. Because NL4-3 infects MDM poorly, NL4-3 was pseudotyped with a YU-2 Env expression plasmid co-transfected in the producer cells as described in Methods. Subsequent spread was blocked in all samples by the addition of entry inhibitors AMD3100 and maraviroc 48 hours post-infection. C) Diagram of the HIV NL4-3 genome. The shaded portion represents the sequence that was replaced with sequence from HIV YU2 to create the NL4-3 env YU-2 chimera. D) Western blot analysis of HEK293T cells transfected with the indicated HIV constructs. E) Virion release from HEK293T transfected as in E as measured by p24 ELISA. ( $n=3$ experimental replicates). F) Relative infection of MOLT4-R5 cells 48 hours after inoculation by the indicated viruses and treated with entry inhibitors as indicated. The frequency of infected cells was 
bioRxiv preprint doi: https://doi.org/10.1101/742197; this version posted August 21, 2019. The copyright holder for this preprint (which was not certified by peer review) is the author/funder, who has granted bioRxiv a license to display the preprint in perpetuity. It is made available under aCC-BY 4.0 International license.

971 measured by intracellular Gag stain and normalized to the untreated condition for each infection. G) Western blot 972 analysis of primary human MDM infected for 10 days with the indicated virus as in $\mathrm{B}$. ( $n=2$ independent donors)

973 H) Summary graph showing virion release as measured by p24 ELISA for primary human MDM infected as in G.

974 Virus production was adjusted for infection frequency as determined flow cytometrically using an intracellular Gag

975 stain. The mean $+/$ - standard deviation is shown. ( $n=4$ independent donors). N.D. - no difference. Statistical

976 significance was determined using a two-tailed, paired $t$-test. N.S. - not significant, ${ }^{* *} p<0.01$. 
bioRxiv preprint doi: https://doi.org/10.1101/742197; this version posted August 21, 2019. The copyright holder for this preprint (which was not certified by peer review) is the author/funder, who has granted bioRxiv a license to display the preprint in perpetuity. It is made available under aCC-BY 4.0 International license.
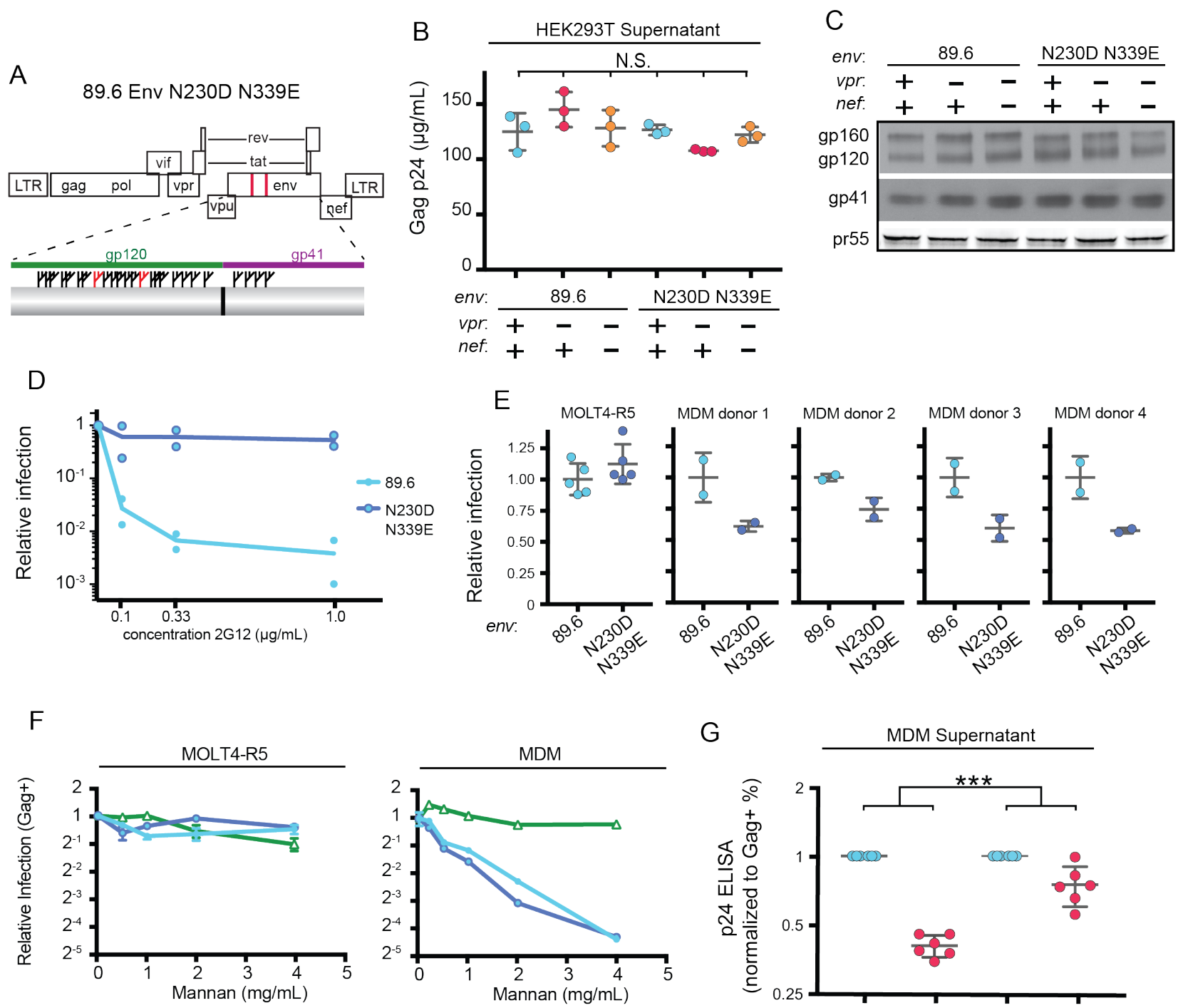

G

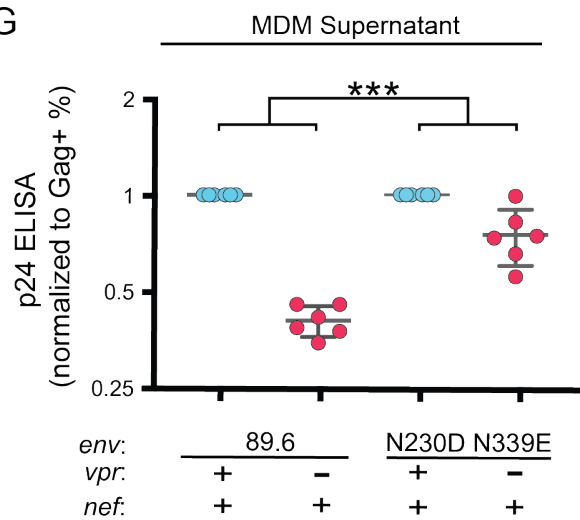

$\mathrm{H}$

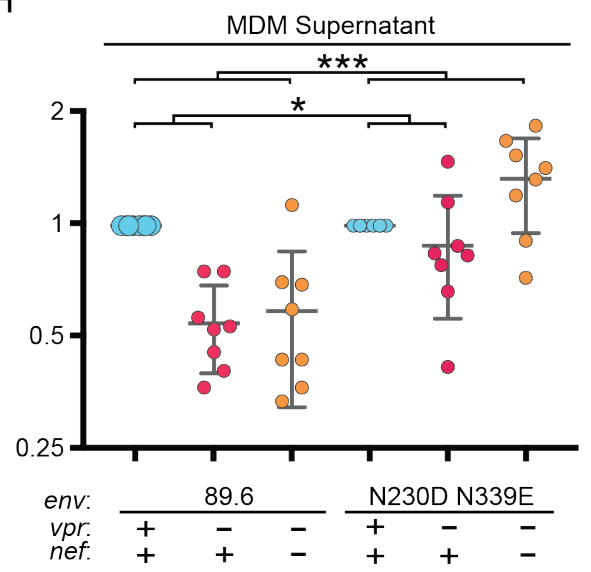

I

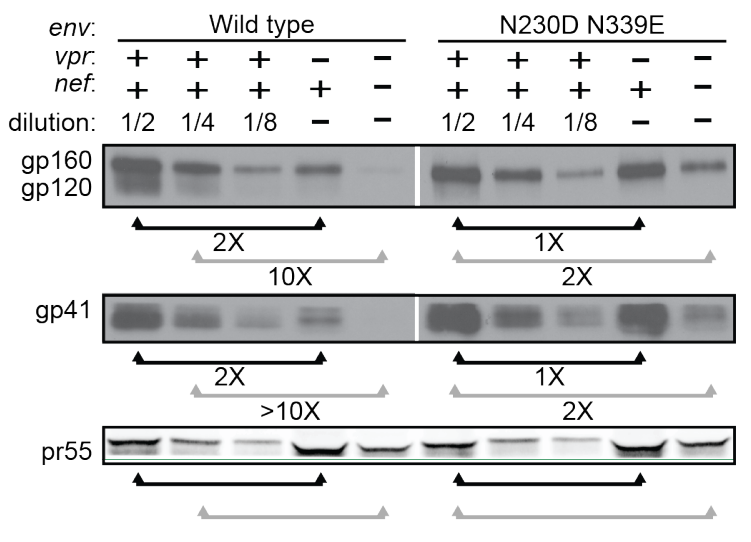

Figure 5: Deletion of $\mathrm{N}$-linked glycosylation sites in env reduces the requirement for $\mathrm{Vpr}$ and Nef for virion release and Env expression in HIV-1 infected primary human MDM. A) Upper panel, diagram of HIV genome encoding the mutations N230D and N339E (indicated in red) to prevent N-linked glycosylation at those sites. Lower panel, diagram of HIV 89.6 N230D N339E mutant Env protein. Branched symbols represent N-linked glycans. B) Summary graph showing virion release from HEK293Ts transfected with the indicated HIV construct as measured by p24 ELISA. ( $n=3$ experimental replicates). Statistical significance was determined by one-way 
bioRxiv preprint doi: https://doi.org/10.1101/742197; this version posted August 21,2019 . The copyright holder for this preprint (which was not certified by peer review) is the author/funder, who has granted bioRxiv a license to display the preprint in perpetuity. It is made available under aCC-BY 4.0 International license.

985 ANOVA. C) Western blot analysis of HEK293T transfected as in B. D) Summary graph showing relative infection frequency of MOLT4-R5 T cells by the indicated HIV following treatment as indicated with the neutralizing antibody 2G12. The percentage of infected cells was measured by intracellular Gag stain and normalized to the untreated condition for each virus. ( $n=2$ independent experiments, both are plotted) E) Summary graphs of relative infection of the indicated cell type by mutant or parental wild type HIV. The frequency of infected cells was measured flow cytometrically by intracellular Gag stain and normalized to the wild-type virus. ( $n=5$ experimental replicates for MOLT4-R5; $n=2$ experimental replicates for MDM from 4 independent donors). F) Summary graph depicting relative infection of the indicated cell type by each virus plus or minus increasing concentrations of mannan as indicated. The frequency of infected cells was measured by intracellular Gag stain and normalized to the uninhibited $(0 \mathrm{mg} / \mathrm{mL}$ mannan) condition for each virus. $89.6 \mathrm{pVSV}-\mathrm{G}$ indicates $89.6 \Delta$ env pseudotyped with VSV-G protein. ( $n=2$ independent donors for 89.6 wild type and $89.6 \Delta$ env pVSV-G; $n=1$ donor for 89.6 env N230D N339E) G) Summary graph of virion release from primary human MDM following 10 days of infection by the indicated HIV as measured by p24 ELISA. Virion release was normalized to the infection frequency assessed flow cytometrically by intracellular Gag stain. The result for each vpr-null mutant was normalized to the vprcompetent virus encoding the same env. ( $n=6$ independent donors) H) Summary graph of virion release from primary human MDM following 10 days of infection by the indicated HIV as measured by p24 ELISA. Virion release was normalized to the infection frequency assessed flow cytometrically by intracellular Gag stain. For this single round infection assay, all viruses were pseudotyped with YU2 Env and viral spread was blocked 48 hours later by addition of AMD3100 and maraviroc. ( $n=8$ independent donors) The result for each vpr-null or vpr-nef-null mutant was normalized to the vpr- and nef-competent virus encoding the same env. I) Western blot analysis of MDM infected as in E. The lysates from the vpr-competent and nef-competent infections were diluted to facilitate comparisons to vpr- and nef-null mutants. ( $n=2$ independent donors) For summary graphs, the means $+/$ standard deviation is shown. In panels $\mathrm{G}$ and $\mathrm{H}$ statistical significance was determined by a two-tailed, paired $t$ test ${ }^{*} p=0.01,{ }^{* *} p<0.01,{ }^{* * *} p<0.001$. 
bioRxiv preprint doi: https://doi.org/10.1101/742197; this version posted August 21,2019 . The copyright holder for this preprint (which was not certified by peer review) is the author/funder, who has granted bioRxiv a license to display the preprint in perpetuity. It is made available under aCC-BY 4.0 International license.

A
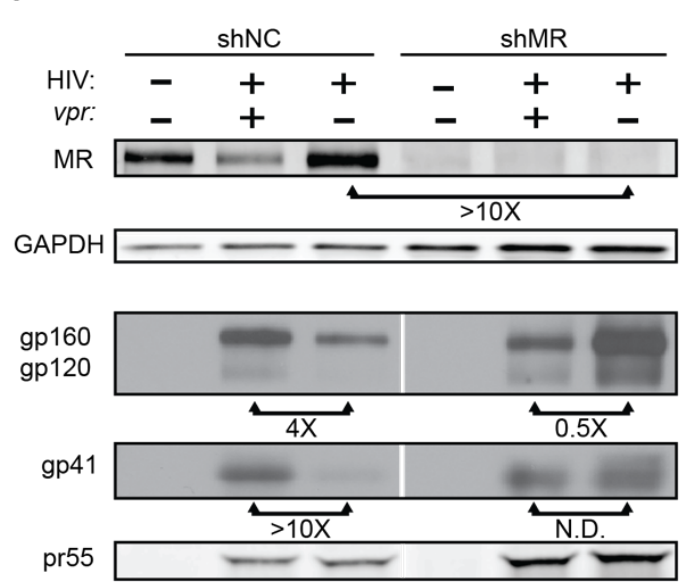

B

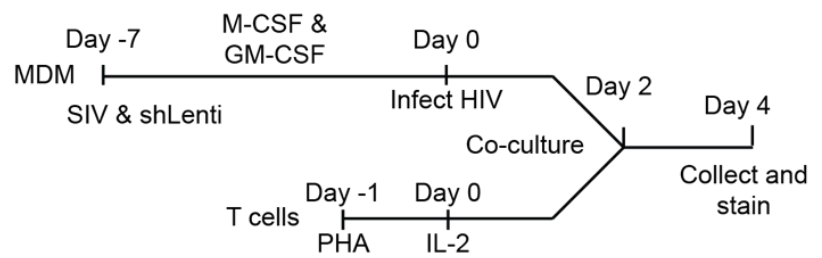

C

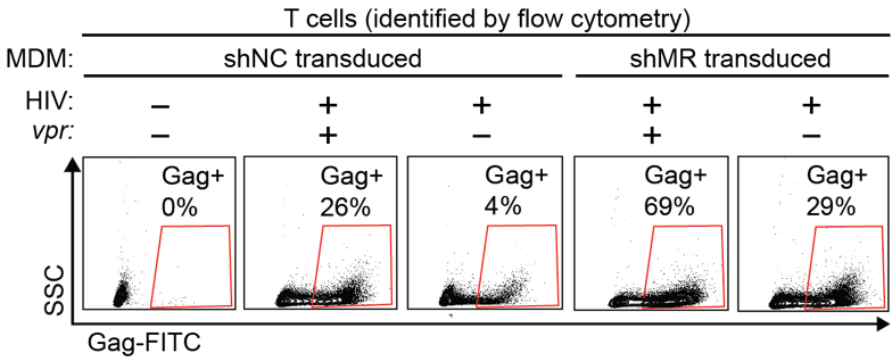

MDM Donor 2
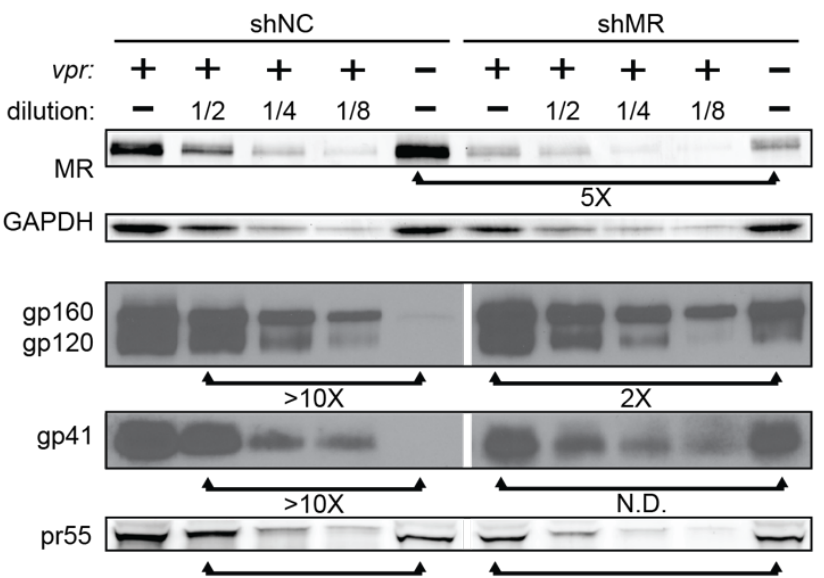

D

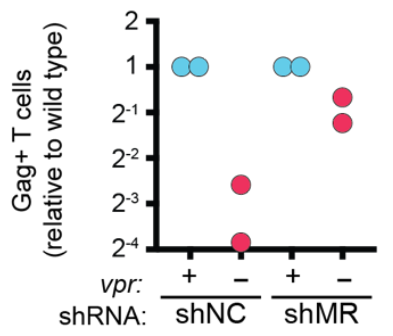

$\mathrm{E}$

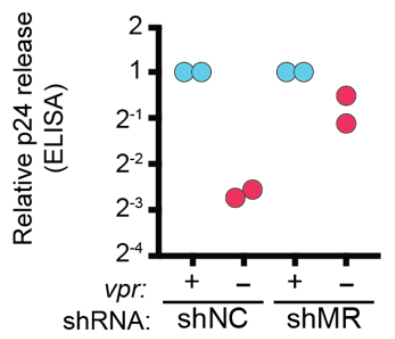

Figure 6: Knockdown of MR enhances Env expression and spread to T cells in vpr-null infection of MDM. A) Western blot analysis of MDM from two independent donors treated with the indicated silencing vector and infected with the indicated HIV for 10 days. The miRNA sequences encoded by the negative control vector (shNC) and the MR silencing vector (shMR) are described in Methods. B) Schematic diagram of experimental protocol used for silencing experiments. C) Representative flow cytometric plots showing frequency of infected $\left(\mathrm{Gag}^{+}\right)$primary $\mathrm{T}$ cells following two days of co-culture with autologous, HIV 89.6 infected primary MDM. T cells were identified in coculture by gating on $\mathrm{CD}^{+} \mathrm{CD} 14^{-}$cells as shown in Fig S2. D) Summary graph displaying relative infection of T cells as measured in $\mathrm{C}$ and normalized to wild type. ( $n=2$ independent donors) $\mathrm{E}$ ) Virus release by co-cultured MDM and T cells as measured by p24 ELISA and normalized to wild type. ( $n=2$ independent donors). 
bioRxiv preprint doi: https://doi.org/10.1101/742197; this version posted August 21,2019 . The copyright holder for this preprint (which was not certified by peer review) is the author/funder, who has granted bioRxiv a license to display the preprint in perpetuity. It is made available under aCC-BY 4.0 International license.
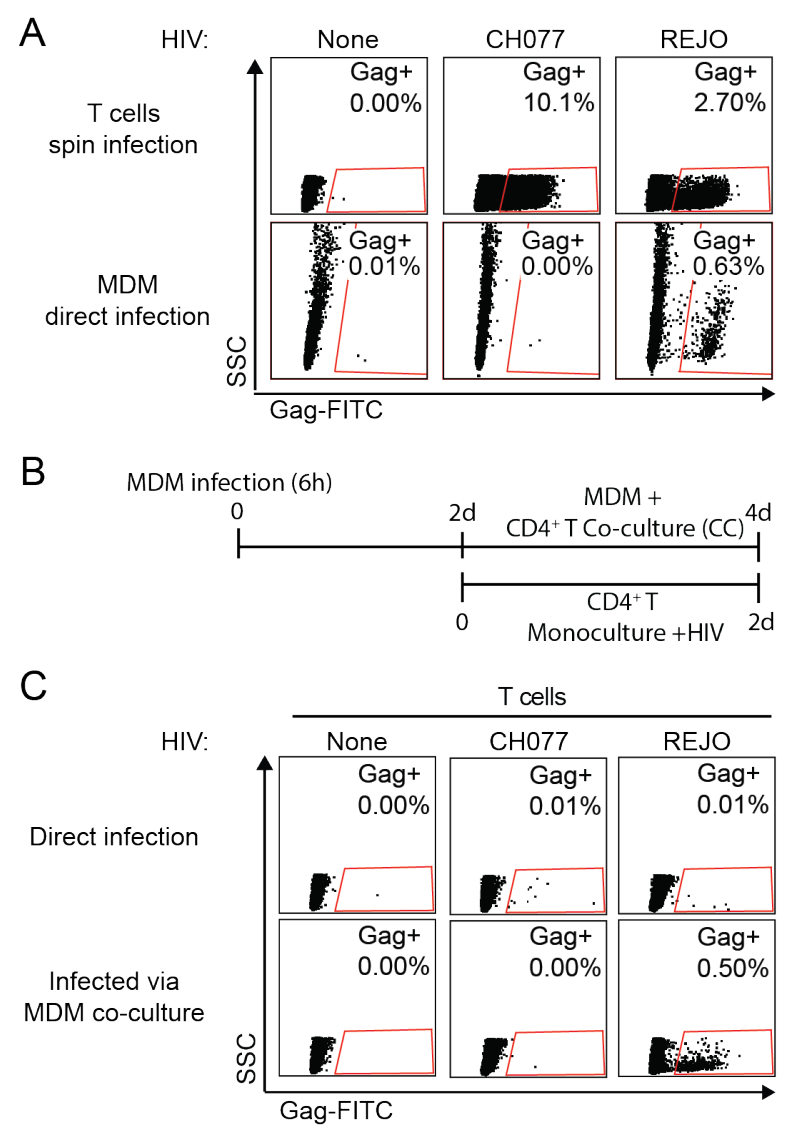

Figure 7: MDM enhance infection of T cells by transmitted/founder (T/F) viruses. A) Flow cytometry plots of primary human T cells 2 days after 2 hour spinnoculation or MDM 4 days after six hour incubation with $50 \mu \mathrm{g}$ of the T/F virus indicated. B) Schematic diagram of protocol for experiments shown in part C. C) Flow cytometry plots to measure the percentage of $\mathrm{Gag}^{+} \mathrm{T}$ cells 2 days after infection by the method indicated. For direct infection, $\mathrm{T}$ cells were continuously cultured with with $50 \mu \mathrm{g}$ of virus over the two day incubation period. For infection via MDM coculture, T cells were co-cultured with MDM transiently exposed to $50 \mu \mathrm{g}$ of virus as in part $\mathrm{A}$. For the co-culture assays, $T$ cells were identified in co-culture by gating on $\mathrm{CD}^{+} \mathrm{CD} 14^{-}$cells. $n=1$ donor. 
A

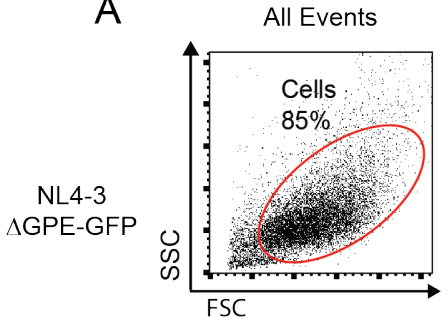

NL4-3 $\triangle$ GPE-GFP

vpr-null

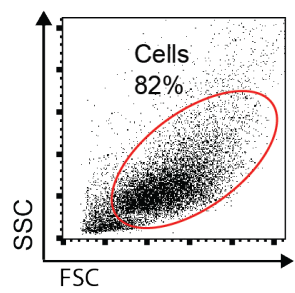

B

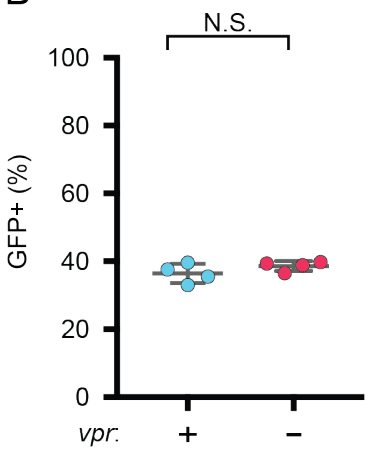

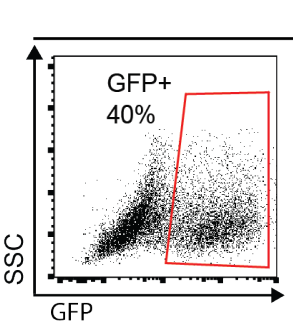

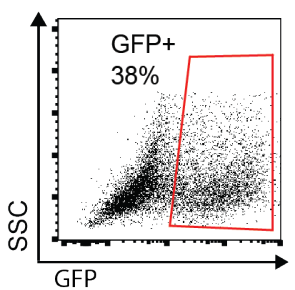

C

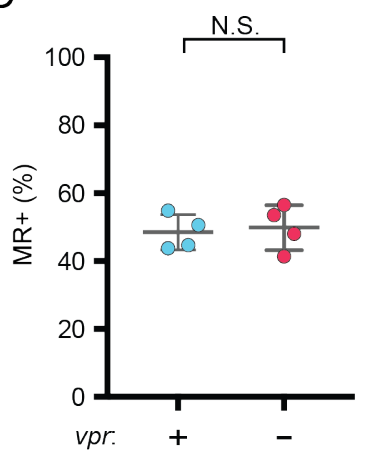

Cells
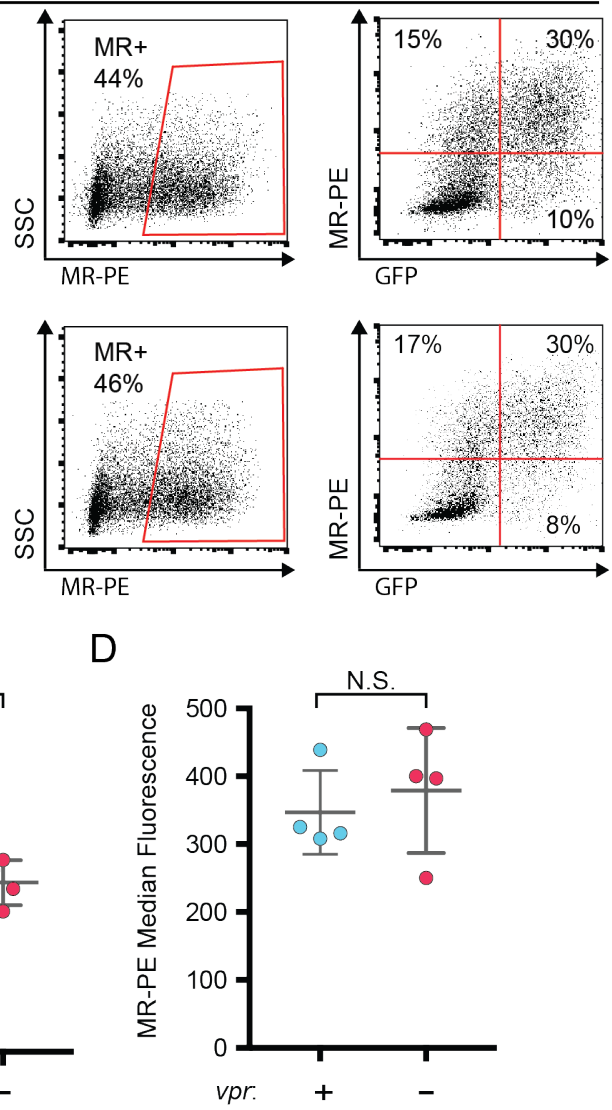

Supplement Figure 1: Vpr does not affect MR expression in co-transfected HEK293T cells. A) Representative flow cytometric analysis of HEK293T cells co-transfected with the indicated GFP-expressing HIV genome (NL4-3 $\triangle$ GPE-GFP plus or minus an intact $v p r$ open reading frame) and an expression vector containing MR (pcDNA3.hMR). The transfections were performed four times and a representative pair of vpr-competent and vprnull transfections was chosen. B) Summary graph showing the percentage of cells that are transfected (GFP+) following co-transfection as in A. C) Summary graph showing the percentage of cells that remain MR+ following cotransfection as in B. D) Summary graph showing the the median MR-PE fluorescence of all cells following cotransfection as in A. For all graphs, the mean plus or minus standard deviation is shown. ( $n=4$ experimental replicates). Statistical significance was determined by a two-tailed, paired $t$-test. N.S. - not significant: $p=0.30$, $\mathrm{p}=0.66$, and $\mathrm{p}=0.57$ respectively. 
bioRxiv preprint doi: https://doi.org/10.1101/742197; this version posted August 21,2019 . The copyright holder for this preprint (which was not certified by peer review) is the author/funder, who has granted bioRxiv a license to display the preprint in perpetuity. It is made available under aCC-BY 4.0 International license.

89.6 wild type

shNC transduced MDM
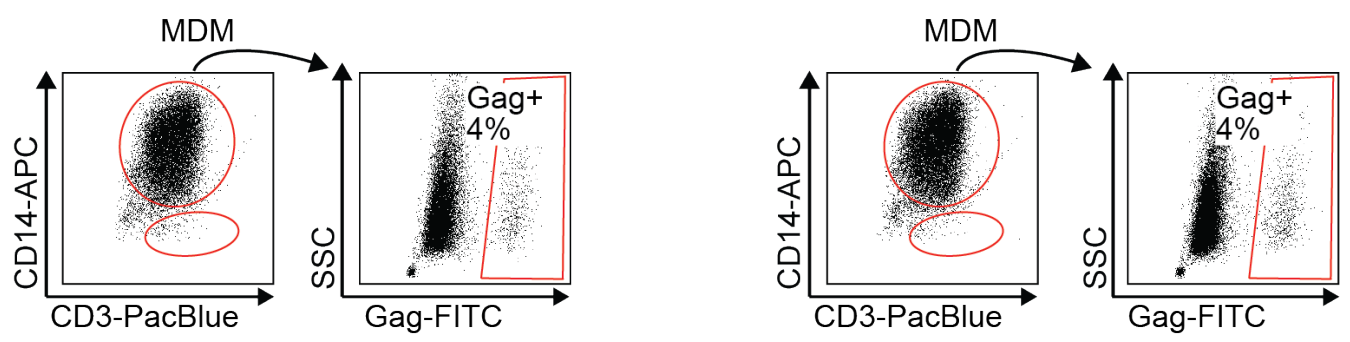

shMR transduced MDM

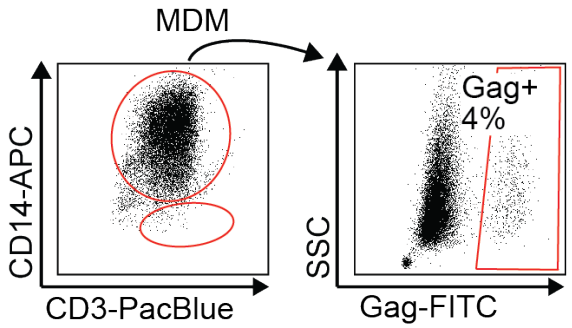

shNC transduced MDM + T cell Co-culture

shMR knockdown

MDM + T cell

Co-culture
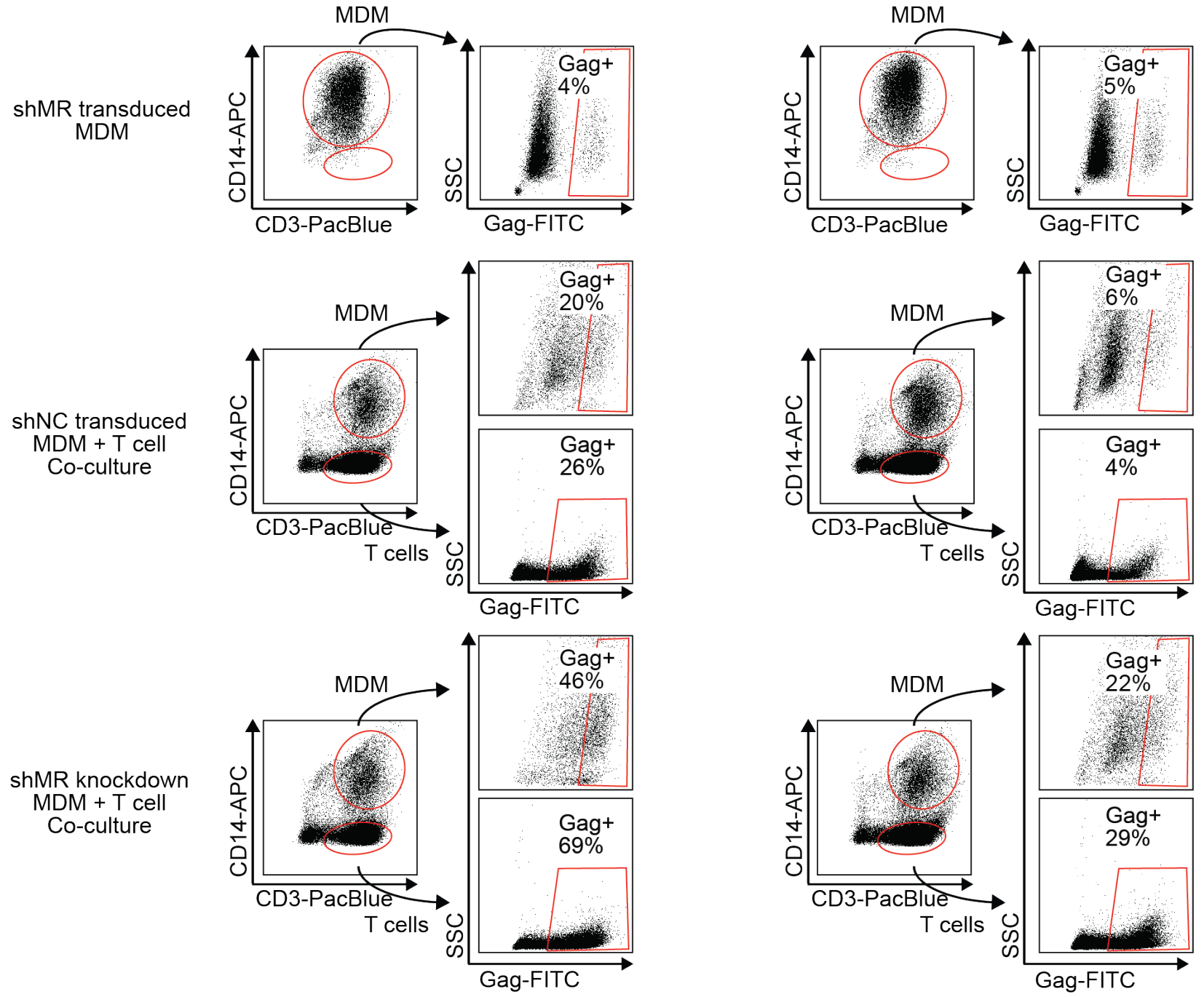

Supplemental Figure 2: T cells and MDM can be identified by flow cytometry and the percentage of each that are Gag+ can be measured separately. Flow cytometric dot plots illustrating segregation of CD14+ MDM from CD3+ T cells in co-cultures and subsequent assessment of HIV-1 infection by intracellular Gag p24 stain after treatment of the indicated cultures treated as shown in Fig 6B. $n=2$ independent donors. Plots from one donor are shown here and Gag+ percentages from both are shown in Figure 6. 